\title{
Future Changes in Drought Characteristics under Extreme Climate Change over South Korea
}

\author{
Joo-Heon Lee, ${ }^{1}$ Hyun-Han Kwon, ${ }^{2}$ Ho-Won Jang, ${ }^{1}$ and Tae-Woong Kim ${ }^{3}$ \\ ${ }^{1}$ Department of Civil Engineering, Joongbu University, Daeja-dong, Deogyang-gu, Goyang-si, Gyeonggi-do 10279, Republic of Korea \\ ${ }^{2}$ Department of Civil Engineering, Chonbuk National University, 567 Baekje-daero, Deokjin-gu, Jeonju-si, \\ Jeollabuk-do 54896, Republic of Korea \\ ${ }^{3}$ Department of Civil \& Environmental Engineering, Hanyang University, 55 Hanyangdaehak-ro, Sangnok-gu, Ansan-si, \\ Gyeonggi-do 15588, Republic of Korea \\ Correspondence should be addressed to Hyun-Han Kwon; hkwon@jbnu.ac.kr
}

Received 1 February 2016; Accepted 23 June 2016

Academic Editor: Jorge E. Gonzalez

Copyright (C) 2016 Joo-Heon Lee et al. This is an open access article distributed under the Creative Commons Attribution License, which permits unrestricted use, distribution, and reproduction in any medium, provided the original work is properly cited.

\begin{abstract}
This study attempts to analyze several drought features in South Korea from various perspectives using a three-month standard precipitation index. In particular, this study aims to evaluate changes in spatial distribution in terms of frequency and severity of droughts in the future due to climate change, using IPCC (intergovernmental panel on climate change) GCM (general circulation model) simulations. First, the Mann-Kendall method was adopted to identify drought trends at the five major watersheds. The simulated temporal evolution of SPI (standardized precipitation index) during the winter showed significant drying trends in most parts of the watersheds, while the simulated SPI during the spring showed a somewhat different feature in the GCMs. Second, this study explored the low-frequency patterns associated with drought by comparing global wavelet power, with significance test. Future spectra decreased in the fractional variance attributed to a reduction in the interannual band from 2 to 8 years. Finally, the changes in the frequency and the severity under climate change were evaluated through the drought spell analyses. Overall features of drought conditions in the future showed a tendency to increase (about 6\%) in frequency and severity of droughts during the dry season (i.e., from October to May) under climate change.
\end{abstract}

\section{Introduction}

There exists a degree of climate variability on all time scales, and floods and droughts are extremes associated with variability in precipitation. Climate variability characterized by a slow-varying oscillation in the climate system can modify the likelihood of hydrologic extreme events. Together with climate variability, climate change is regarded as another potential driver for modifying the hydrological cycle [1-3]. Climate change refers to any long-term, significant change in the expected patterns of average weather in a specific region [4]. It has been widely acknowledged that the frequency and magnitude of extreme hydrologic events can be modulated by enhanced climate variability driven by climate change $[1,3,5]$. According to the precipitation outlook based on climate change scenarios [4], increasing concentrations of greenhouse gases are likely to trigger very different patterns of heavy rain, extreme drought, and heavy snow in some regions [6].

In recent decades, extreme drought events seem to be growing in frequency in many countries [7-10]. The frequency of a specific hydrologic variable, especially, should not be treated independently of the frequency of the generating mechanisms $[1,3,11,12]$. There is evidence of a spatiotemporal organization for drought, which takes the form of bandlimited and quasi-oscillatory variations, seen with the El Niño-Southern Oscillation. The rainfall data for South Korea exhibits long memory or regimes with quasi-oscillatory behavior that may derive from low-frequency Pacific and Indian Ocean climate modes [1]. The connection between these low-frequency climate modes and rainfall in South Korea has been noted by several researchers $[1,13,14]$.

In terms of investigating drought variability and trends, Kwon and Moon [15] employed a wavelet transform (WT) 
analysis method and assessed its applicability to hydrologic time series. Kwon and Moon [16] investigated teleconnections between the El Niño/La Niña-Southern Oscillation (ENSO) index and the Palmer Drought Severity Index (PDSI) with respect to low-frequency modulation. They utilized cross wavelet transform and Multichannel Singular Spectrum Analysis (MSSA) as the main tool for the decomposition of time series. Kim [17] analyzed the variability of precipitation in California, USA, using the WT, and Yoon et al. [18] assessed major historical drought events in terms of duration based on the drought index for each duration in each district. Kim et al. [19] applied a nonparametric Mann-Kendall (MK) statistical trend test to SPI for the representative watersheds in South Korea.

South Korea has been already classified by the United Nations as a country suffering from a more than moderate water shortage. Indeed, South Korea has experienced much more frequent and extreme droughts and floods since the late 1990s [20], and drought risk is likely to increase over the course of the twenty-first century due to climate change $[6,21]$. In addition, South Korea is very vulnerable to droughts because most of the cities in South Korea are densely populated with the extensive land use changes, so that meteorological disasters associated with the enhanced droughts are expected to become more severe. In the light of the above, a main objective of this study is first to understand the observed changes in drought and to further examine the relationship between drought and climate change. In this study, we analyzed the statistical features of past droughts that occurred in South Korea and future changes in drought patterns using the SPI as a representative meteorological drought index. The MK and WT were used as a main tool to characterize the trend and variability of drought. In the past, Fourier transforms (FT) have been used extensively to decompose and analyze climate time series data. This type of representation of the underlying signal assumes that climate processes are stationary, with linear, oscillatory dynamics and with fixed amplitudes and phases embedded in a short memory noise process. However, many hydroclimatological processes demonstrate strong nonstationary and nonlinear dynamics [22-24]. Therefore, the adoption of stationary and linear assumptions and the use of FT may not be appropriate in terms of understanding the underlying dynamics [25]. A WT analysis allows a frequency decomposition of the signal with time-varying amplitudes and phases and considers nonlinear oscillation dynamics, which is arguably more useful in understanding climate variability in space and time. Torrence and Compo [26] introduced various WT analysis methods using their application methods with ENSO time series. In addition, Grinsted et al. [27] applied cross wavelet transform and wavelet coherence analysis methods to better analyze underlying variability for various time series. Finally, this study investigated the drought variability, in terms of magnitude and occurrence frequency for five major watersheds in South Korea which were analyzed. The results of our study have the potential to improve water resource management in this region by highlighting management decisions that help to decrease vulnerability to droughts and other crises related to climate variability.
A brief summary of the main concept of this study was presented in this section. Section 2 describes the data set used to investigate the droughts. The relevant theoretical aspects of the MK test and WT analysis are introduced in Section 3. Changes in the trends, periodicities, and frequencies of drought under climate change are described in Section 4. Section 5 includes a discussion and the conclusions.

\section{Data}

2.1. Watershed and Climate Data. The aim of this study was to analyze drought variability for five major watersheds in South Korea (i.e., watersheds of the Han River, Nakdong River, Geum River, Seomjin River, and Yeongsan River). For this research, the primary data is daily levels of precipitation for the Korean Peninsula, and the data is accumulated on a monthly basis for the SPI analysis. In this first respect, of the 77 weather stations operated by the Korea Meteorological Administration (KMA), we select 54 stations that are directly relevant for drought patterns and for which long-term reliable data are readily available (see Figure 1 ). The remaining 23 stations were excluded because the weather data on record covered periods of less than 30 years. Each site has a different period of record, and there are no missing values. The period of record of precipitation data analyzed here extends from 1976 to 2010, during which full records are available at each station. Both Thiessen and Inverse Distance Weight (IDW) are the simplest commonly used method for estimating areal rainfall. However, Thiessen often provides abrupt implausible change at polygon boundaries. Thus, these series were used for estimating the areal rainfall, using the IDW method. Second, the areal monthly rainfall was used to derive the three-month SPI for each watershed. The observed rainfall data, spanning from 1976 to 2010, were used in conjunction with precipitation simulations from 1976 to 2099 projected by four GCMs. Figure 1(a) shows the weather stations that are used for calculating the SPI. In Figure 1(b), the area in blue represents the 20 medium-size catchments in the Korean Peninsula and indicates the watersheds of the five major rivers analyzed in this study. Tables 1 and 2 show information for the weather stations and the representative watersheds. The watersheds of the Han River, Nakdong River, Geum River, Seomjin River, and Yeongsan River account for approximately $68 \%$ of the area of South Korea.

2.2. GCMs and Downscaling. The four GCMs (i.e., CNRMCM3, CSRIRO-MK3, CONS-ECHOG, and UKMO-HADCM) for the worst case climate change scenario from the IPCC GCM studies are described in Table 3.

GCMs have been used to reproduce historical climate models, understand climate mechanisms, and generate forecasts and projections of teleconnections and the interannual variability of sea surface temperature, among other things. GCMs have been claimed useful for long-term climate change projections $[28,29]$ as well as for short-term seasonal forecasts $[2,30-33]$, though these are often used with some type of dynamical or statistical downscaling technique. GCM-based analysis is constrained by the understanding of atmospheric dynamics at scales greater than 2 degrees of 


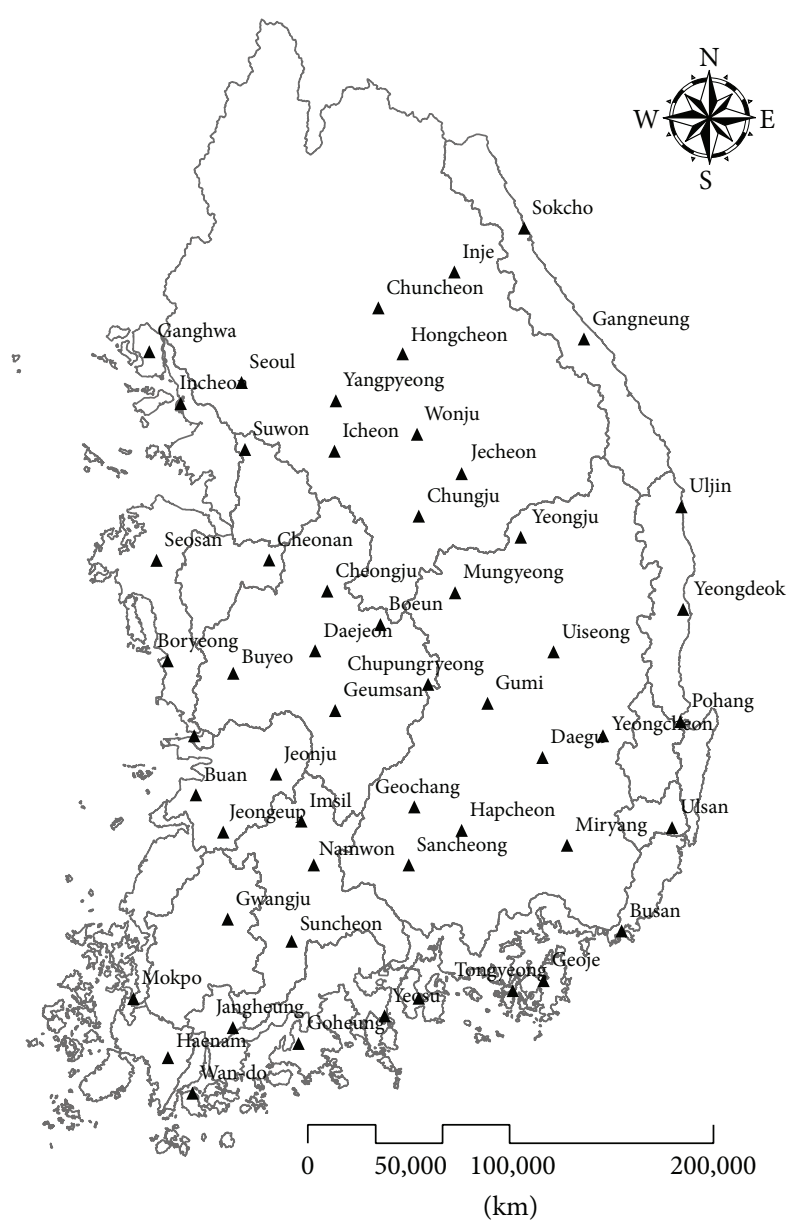

(a) 54 weather stations in Korea

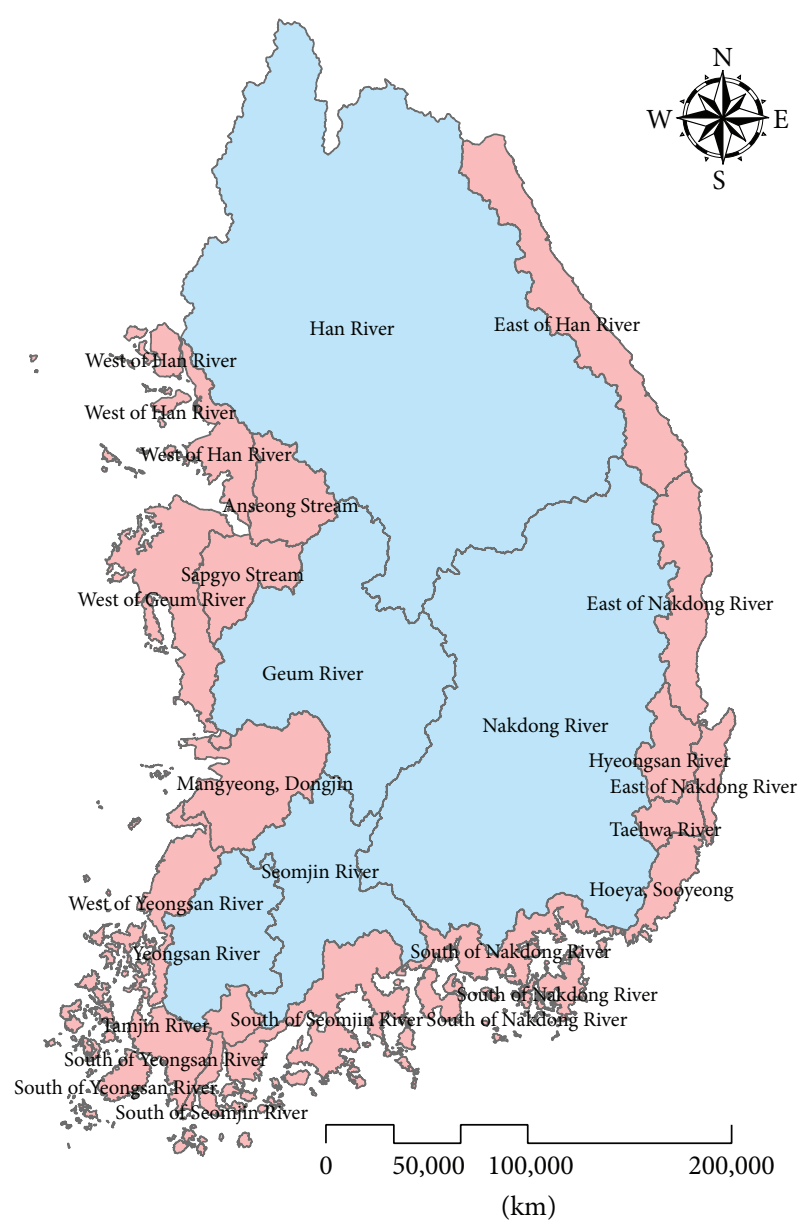

(b) 20 watersheds in Korea

Figure 1: The locations of the 54 automated weather stations and the five major watersheds (Han River, Nakdong River, Geum River, Seomjin River, and Yeongsan River) of Korea.

longitude and latitude, and thus using downscaling models to reproduce the underlying physics could elicit better analyses at finer spatial and temporal scales [34]. Specifically, the daily precipitation data have significant variability, are distinctively non-Gaussian, exhibit relatively complicated spatiotemporal dependence [35], and cannot be easily derived from atmospheric dynamic equations [34]. To solve these limitations, there are two primary approaches to downscale climate model outputs: statistical downscaling and dynamic downscaling using a regional climate model (RCM). It is not technically feasible to operate dynamic downscaling at the required spatial and temporal resolution, from multiple models due to computational load. In addition, it has been acknowledged that precipitation simulations from RCMs are still biased due to limited understanding of regional climate process. Therefore, statistical postprocesses associated with bias correction are generally needed before being used for climate impact assessment [36-42]. This inherent complexity has led to the development of statistical downscaling models to relate climate variables to synoptic atmospheric patterns (e.g., $[32,33,35])$. The downscaling of these GCM simulations to a regional scale is generally employed for hydrological climate impact studies and results in bias corrected information on local-scale climate change (e.g., [36, 43-46]). In this study, a hybrid spatiotemporal downscaling based on a transfer function and a weather generator was applied. One may expect a direct use of the bias corrected monthly precipitation without the temporal downscaling, but the projections of change to rainfall extremes may be still underestimated. Therefore, this study used the monthly precipitation data aggregated from the downscaled daily precipitation time series to better assess the changes in drought risk.

For the spatial bias correction of the GCMs to the 54 weather stations, the transfer function method based on the Cyclostationary Empirical Orthogonal Function (CSEOF) [47] and a multiple linear regression method were employed, and the statistical relationships were calculated between large-area and site-specific surface climates (e.g., precipitation and temperature). It has been acknowledged that the CSEOF analysis provides significant advantages over EOFs (empirical orthogonal functions) when dealing with signals such as modulated annual cycles and ENSO signals [48]. In 
TABLE 1: Weather stations of the KMA used in this study.

\begin{tabular}{|c|c|}
\hline Code & Name \\
\hline 90 & Sokcho \\
\hline 101 & Chuncheon \\
\hline 105 & Gangneung \\
\hline 108 & Seoul \\
\hline 112 & Incheon \\
\hline 114 & Wonju \\
\hline 119 & Suwon \\
\hline 127 & Chungju \\
\hline 129 & Seosan \\
\hline 130 & Uljin \\
\hline 131 & Cheongju \\
\hline 133 & Daejeon \\
\hline 135 & Chupungryeong \\
\hline 138 & Pohang \\
\hline 143 & Daegu \\
\hline 146 & Jeonju \\
\hline 152 & Ulsan \\
\hline 156 & Gwangju \\
\hline 159 & Busan \\
\hline 162 & Tongyeong \\
\hline 165 & Mokpo \\
\hline 168 & Yeosu \\
\hline 170 & Wan-do \\
\hline 201 & Ganghwa \\
\hline 202 & Yangpyeong \\
\hline 203 & Icheon \\
\hline 211 & Inje \\
\hline 212 & Hongcheon \\
\hline 221 & Jecheon \\
\hline 226 & Boeun \\
\hline 232 & Cheonan \\
\hline 235 & Boryeong \\
\hline 236 & Buyeo \\
\hline 238 & Geumsan \\
\hline 243 & Buan \\
\hline 244 & Imsil \\
\hline 245 & Jeongeup \\
\hline 247 & Namwon \\
\hline 256 & Suncheon \\
\hline 260 & Jangheung \\
\hline 261 & Haenam \\
\hline 262 & Goheung \\
\hline 272 & Yeongju \\
\hline 273 & Mungyeong \\
\hline 277 & Yeongdeok \\
\hline 278 & Uiseong \\
\hline 279 & Gumi \\
\hline 281 & Yeongcheon \\
\hline 284 & Geochang \\
\hline 285 & Hapcheon \\
\hline 288 & Miryang \\
\hline 289 & Sancheong \\
\hline 294 & Geoje \\
\hline 295 & Namhae \\
\hline
\end{tabular}

TABLE 2: Five major watersheds' ID and area $\left(\mathrm{km}^{2}\right)$ for drought analysis.

\begin{tabular}{lcc}
\hline Basin name & ID & Area $\left(\mathrm{km}^{2}\right)$ \\
\hline Han River & 10 & 23,293 \\
Anseong Stream & 11 & 1,659 \\
West of Han River & 12 & 1,993 \\
East of Han River & 13 & 3,338 \\
Nakdong River & 20 & 23,702 \\
Hyeongsan River & 21 & 1,140 \\
Taehwa River & 22 & 661 \\
Hoeya/Sooyeong & 23 & 865 \\
East of Nakdong River & 24 & 2,895 \\
South of Nakdong River & 25 & 2,449 \\
Geum River & 30 & 9,914 \\
Sapgyo Stream & 31 & 1,668 \\
West of Geum River & 32 & 2,932 \\
Mangyeong, Dongjin & 33 & 3,023 \\
Seomjin River & 40 & 4,914 \\
South of Seomjin River & 41 & 3,385 \\
Yeongsan River & 50 & 3,470 \\
Tamjin River & 51 & 506 \\
South of Yeongsan River & 52 & 1,507 \\
West of Yeongsan River & 53 & 2,117 \\
\hline
\end{tabular}

other words, the CSEOF represents the complete spatiotemporal evolution of prominent climate signals (e.g., seasonal cycle, prominent intraseasonal oscillation, and ENSO-related evolution) over a cyclic period [48]. For the temporal downscaling, a weather generator (WXGEN) [49-51] was used to downscale monthly precipitation to daily precipitation. The WXGEN developed by Richardson [52] incorporates a first-order Markovian process for rainfall occurrences in the simulation process and utilized a skewed normal distribution for simulation of rainfall amounts. Among many stochastic weather generators, the WXGEN is a more comprehensive package which allows simultaneous generation of daily precipitation, maximum temperature, minimum temperature, relative humidity, and wind velocity, among other factors, based on the statistics of the observed climate variables [53]. The WXGEN embedded in SWAT [54] has been widely used in several studies to generate missing weather data [55-57] and climate change scenarios [58-60]. The WXGEN is based on a first-order Markov chain model to simulate daily precipitation occurrences, and the precipitation amount is then generated by a non-Gaussian distribution such as gamma distribution. The parameters in the WXGEN include monthly frequency of wet and dry day sequences, statistical moments (i.e., mean, standard deviation, and skewness) of monthly precipitation, daily air temperature, and daily solar radiation. The WXGEN uses a multivariate stochastic model to simulate maximum and minimum temperature and solar radiation. The time series is first normalized by monthly means and standard deviation. The anomaly series can be written as follows:

$$
X_{i, j}(k)=\alpha X_{i, j-1}(k)+\beta \omega_{i, j}(k),
$$


TABLE 3: Detailed information on the four GCMs used in this study.

\begin{tabular}{lcccc}
\hline Number & \multirow{2}{*}{ Model (agency-version) } & Country & Spatial resolution \\
& & & Atmospheric & Oceanic \\
\hline 1 & CNRM-CM3 & France & $128 \times 64$ & $180 \times 170$ \\
2 & CSIRO-MK3 & Australia & $192 \times 96$ & $192 \times 189$ \\
3 & CONS-ECHOG & Germany/Korea & $96 \times 48$ & $128 \times 117$ \\
4 & UKMO-HADCM & UK & $96 \times 73$ & $288 \times 144$ \\
\hline
\end{tabular}

where $X_{i, j}(k)$ is a $k \times 1$ matrix for day $j$ of year $i$ whose elements are the anomalies of maximum temperature $(k=1)$, minimum temperature $(k=2)$, and solar radiation $(k=3)$. $\omega_{i, j}(k)$ is a $k \times 1$ matrix for normally distributed random variables with a mean of zero and a variance of unity, and $\alpha$ and $\beta$ are $k \times k$ matrices whose elements are defined so that the observed cross-correlations are reproduced. Here, the daily values of the weather variables are simulated by multiplying the anomalies by the monthly standard deviation and then adding the monthly mean [61]. For details please refer to previous publications [49-51,55-60]. Again, note that the subsequent analyses are based on monthly precipitation data aggregated from the downscaled daily precipitation time series.

2.3. Standardized Precipitation Index. In this study, we used an SPI to assess the spatial and temporal characteristics of future drought and specifically aimed to assess the potential meteorological drought risk rather than the hydrological drought risk in consideration of the ability to supply water and to better highlight needs specific to facilities for supplying water sources. McKee et al. [62, 63] developed the standardized precipitation index (SPI) for the purpose of defining and monitoring precipitation deficits on multiple timescales. The SPI is a simple index calculated from a long-term record (at least 30 years) of precipitation for individual weather stations. The data is first fitted to a two-parameter gamma distribution and normalized to a flexible multiple time scale. The shape and scale parameters of the gamma distribution are estimated for each station, for each timescale of interest $(1,2,3, \ldots$ months $)$, and for each month of the year. The SPI is well suited for risk management and can provide early warnings of drought risk and severity because it is able to explicitly specify this information for each geophysical location.

To calculate the SPI, gamma distribution needs to be transformed to the standard normal random variable, with mean zero and variance one, which is the value of the SPI. Thom [64] found that the gamma distribution is well suited to fit monthly precipitation time series. The gamma probability density function using the shape-scale parametrization is

$$
f(x)=\frac{1}{\beta^{\alpha} \Gamma(\alpha)} x^{\alpha-1} e^{-x / \beta}, \text { for } x>0,
$$

where $\alpha>0$ is a shape factor, $\beta>0$ is a scale factor, and $x>0$ is the amount of precipitation. $\Gamma(\alpha)>0$ is the gamma function, which is defined as

$$
\Gamma(\alpha)=\int_{0}^{\infty} x^{\alpha-1} e^{-x} d x .
$$

Fitting the gamma distribution to the data requires estimating parameters and this study used a maximum likelihood method suggested by Thom [64]:

$$
\begin{aligned}
& \widehat{\alpha}=\frac{1}{4 A}\left(1+\sqrt{1+\frac{4 A}{3}}\right) \\
& \widehat{\beta}=\frac{\bar{x}}{\widehat{\alpha}} \\
& A=\ln (\bar{x})-\frac{\sum \ln (x)}{n},
\end{aligned}
$$

where $n$ is number of precipitation observations.

The resulting parameters are then used to determine the cumulative probability of an observed precipitation event for the given month and time scale:

$$
F(x)=\frac{1}{\widehat{\beta}^{\widehat{\alpha}} \Gamma(\widehat{\alpha})} \int_{0}^{x} x^{\widehat{\alpha}-1} e^{-x / \widehat{\beta}} .
$$

Substituting $t$ for $x / \widehat{\beta}$, the equation becomes an incomplete gamma function. Since the gamma function is not defined for $x=0$ and a precipitation distribution may have many zeros, the cumulative probability density function can be written as follows:

$$
D(x)=p+(1-p) F(x),
$$

where $p$ is the probability of zero precipitation, and the probability $p$ is simply estimated by a ratio of the number of zeros in the time series over the total number of data [65], and the cumulative probability $D(x)$ is estimated by using the incomplete gamma. The cumulative probability, $D(x)$, is then projected to the standard Gaussian distribution so as to transform the probability of the gamma distribution into normal random variable $Z$ with mean zero and variance one, which is the value of the SPI. This can be regarded as an equiprobability mapping approach allowing us to retain the essential statistical properties of transforming a variate from the gamma distribution to a variate with the standard normal distribution [66], as illustrated in Figure 2. In other words, the precipitation is first transformed to uniformly distributed values $(0,1)$ through the fitted gamma CDF, and these uniform values are then transformed to normally distributed data by using the inverse of the normal cumulative distribution function. The standardized anomaly is finally calculated with results having an average of zero and a standard deviation of one, and the transformation was implemented in Matlab. A dashed red line and solid blue line in the left side of Figure 2 


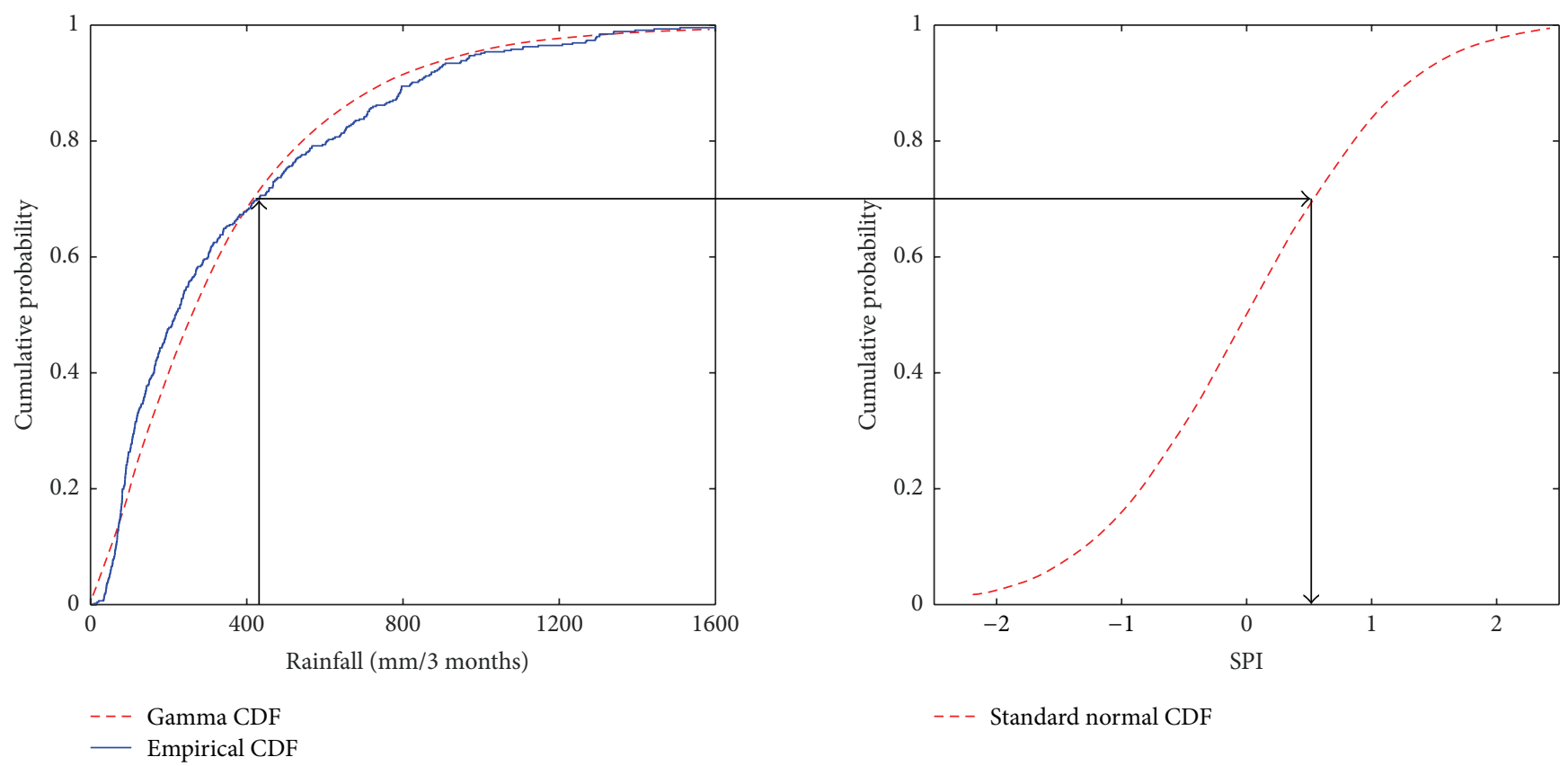

FIGURE 2: An example of (equiprobability) transformation of the three-month precipitation for Seoul from cumulative probability of fitted gamma cumulative distribution into normal random variable $Z$ (SPI) with mean zero and variance one.

TABLE 4: A classification of the SPI that classifies the SPI into extreme, severe, and moderate classes for both wet and dry moisture condition.

\begin{tabular}{lc}
\hline SPI value & Drought class \\
\hline More than +2.00 & Extremely wet \\
+1.50 to +1.99 & Very wet \\
+1.00 to +1.49 & Moderately wet \\
+0.99 to -0.99 & Near normal \\
-1.00 to -1.49 & Moderately dry \\
-1.50 to -1.99 & Severely dry \\
Less than -2.00 & Extremely dry \\
\hline
\end{tabular}

indicate the cumulative probability of the fitted gamma distribution and the empirical cumulative density function of the accumulated three-month precipitation for Seoul station for the period 1976-2010, respectively. The dashed red line in the right hand side of Figure 2 denotes the cumulative probability of the standard normal random variable $Z$ (or SPI value) using the same cumulative probability scale of the fitted gamma distribution on the left hand side of the figure. In this study, this transformation procedure was used to transform a given three-month precipitation to SPI value.

McKee et al. [62] proposed classifying the SPI into extreme, severe, and moderate states for both wet and dry condition as shown in Table 4. This classification has been adopted by KMA (Korea meteorological agency) that makes use of the SPI officially to define the severity and the frequency of the precipitation deficit. For this study, we used a three-month SPI, which is calculated on a monthly basis for a moving window of three months, where the rainfall is summed over the window for each month.

\section{Methods}

In this study, the WT and the MK test are used to determine possible changes in drought series and to further examine the relationship between drought and climate change. A brief description of the above-mentioned methodology is provided in the following section.

3.1. Mann-Kendall Trend Test. In this study, the MK test is used in place of a parametric linear regression model to analyze significant changes in drought patterns. The purpose of the Mann-Kendall (MK) test [67-69] is to statistically assess if there is a monotonic trend of the variable of interest over time. The monotonic trend indicates that the variable consistently increases (or decreases) over time, but the trend may be linear or nonlinear. The residuals from the linear regression model assume being normally distributed while the assumption is not required by the MK test. In other words, the MK test is a nonparametric (distribution-free) test. This rank-based test is ideal for the nonnormality of hydrological variables (e.g., precipitation and discharge). If the test statistic is significantly different from zero, the null hypothesis $\left(H_{0}\right)$ of no monotonic trend is rejected and accepts the alternative hypothesis $\left(H_{a}\right)$ of monotonic trend and vice versa [70]. The MK test is conducted as follows. First, determine the sign of all $(n-1) / 2$ possible differences $x_{j}-x_{i}$, where $j>i$. Second, compute MK statistic $S$ as follows:

$$
S=\sum_{i=1}^{n-1} \sum_{j=i+1}^{n} \operatorname{sign}\left(x_{j}-x_{i}\right) \text {, }
$$


where $x_{j}$ are the sequential data values, $n$ is the total number of data points in the set, and $\operatorname{sign}(x)$, an indicator function, is defined as

$$
\operatorname{sign}(x)= \begin{cases}1, & \text { if } x_{j}-x_{i}>0 \\ 0, & \text { if } x_{j}-x_{i}=0 \\ -1, & \text { if } x_{j}-x_{i}<0\end{cases}
$$

If $S$ is a positive value, observations obtained later in time tend to be larger than observations made earlier and vice versa. When $n$ is greater than 8 , the statistic $S$ is approximately normally distributed with mean $E(S)=0$. Third, compute the variance of $\mathrm{MK}$ statistic $S$ as follows:

$$
\operatorname{Var}(S)=\frac{[n(n-1)(2 n+5)]}{18} .
$$

Fourth, standardized MK statistic $Z_{\mathrm{MK}}$ is finally calculated as follows:

$$
Z_{\mathrm{MK}}= \begin{cases}\frac{S-1}{\sqrt{\operatorname{Var}(S)}}, & \text { if } S>0 \\ 0, & \text { if } S=0 \\ \frac{S+1}{\sqrt{\operatorname{Var}(S)}}, & \text { if } S<0 .\end{cases}
$$

If $\left|Z_{\mathrm{MK}}\right|>Z_{1-\alpha / 2}$, null hypothesis $\left(H_{0}\right)$ is rejected and a statistically significant trend exists in the time series. The critical value of $Z_{1-\alpha / 2}$ for a $p$ value of 0.05 and 0.1 from the standard normal distribution is 1.96 and 1.645 , respectively.

3.2. Wavelet Transform Analysis. A change in the variance of a distribution will have a larger effect on the frequency of extremes than a change in the mean $[71,72]$. WT-based time series analysis is employed to investigate changes in the variability of a distribution and to identify both the temporal and spatial aspects of droughts. WT methods have been widely applied to geophysical time series analysis for the past ten years [73]. We summarize the WT analysis as presented by Torrence and Compo [26]. The term wavelets refers to sets of functions of the form $\varphi_{b, a}(t)=|a|^{-0.5} \varphi((t-b) / a)$, that is, sets of functions formed by the dilation and translation of a single function, $\varphi(t)$, known as the mother wavelet. The continuous WT of a real time series $x(t)$ is defined by [74]

$$
X(b, a)=|a|^{-1 / 2} \int_{-\infty}^{+\infty} x(t) \varphi^{*}\left(\frac{(t-b)}{a}\right) d t
$$

where $X(b, a)$ is the wavelet spectrum, $\varphi(t)$ is the wavelet function, $(*)$ denotes the complex conjugate, $b$ is the translation (shift) parameter, and $a \neq 0$ is the scale parameter.

By localizing the wavelet function at $t-b=0$ and computing the coefficients $X(b, a)$, it is possible to examine the behavior of $x(t)$ near $t=b$. A variety of wavelet functions have been proposed $[26,75]$. In this study, the Morlet wavelet was used, which is defined as $\varphi(t)=\pi^{-1 / 4} e^{i \omega_{0} t} e^{-t^{2} / 2}$, where $\omega_{0}$ is the frequency. The Morlet wavelet is a good choice, since it provides a good balance between time and frequency localization [27]. In order to estimate the continuous wavelet transform, an $N$ times convolution of the function shown in (11) is conducted for each scale, where $N$ is the number of points in the time series [76]. Numerically, we were able to estimate wavelet power spectrum in Fourier space, at a given $N$ points, using a discrete Fourier transform $\left(x_{n}\right)$ as [26]. In other words, by choosing $N$ points, the convolution theorem allows us to do all $N$ convolutions simultaneously in Fourier space so that it is much faster to do the estimations. The discrete Fourier transform of $x_{n}$ can be written as

$$
\widehat{x}_{j}=\frac{1}{N} \sum_{n=0}^{N-1} x_{n} \exp \left(-\frac{\pi i j n}{N}\right),
$$

where $j=0, \ldots, N-1$ is the frequency index.

In a continuous limit, the Fourier transform of a function $\varphi(t / a)$ is given by $\widehat{\varphi}(a \omega)$. According to the convolution theorem, the wavelet transform is the inverse Fourier transform of the product:

$$
X_{n}(a)=\sum_{j=0}^{N-1} \widehat{x}_{j} \widehat{\varphi}^{*}\left(a \omega_{j}\right) \exp \left(i \omega_{j} n \delta_{t}\right) .
$$

Information for the wavelet power spectrum can be interpreted at each time and scale. A time-integrated variance of the energy coefficients at every scale is introduced to determine the global wavelet power [26]:

$$
{\overline{X_{n}}}^{2}(a)=\frac{1}{N} \sum_{n=0}^{N-1}\left|X_{n}(a)\right|^{2} \text {. }
$$

Another way to interpret information in the wavelet power spectrum at each time and scale is scale integrated variance of energy coefficients over time to compute the scale averaged wavelet power (SAWP) as

$$
\bar{X}_{n}^{2}(t)=\frac{\delta_{j} \delta_{t}}{C_{\delta}} \sum_{j=j_{1}}^{j_{2}} \frac{\left|X_{n}\left(a_{j}\right)\right|^{2}}{a_{j}} .
$$

$C_{\delta}$ is reconstruction coefficient and is a constant for each wavelet function. $j_{1}$ and $j_{2}$ are scales over which the averaging takes place. $\delta_{j}$ and $\delta_{t}$ are the scale averaging coefficient and sampling period, respectively.

Wavelet transform can reconstruct the original time series using either deconvolution or the inverse filter because it is a bandpass filter with a known wavelet function. The reconstructed time series can be estimated by the sum of the real part of the wavelet transform over all scales:

$$
x_{n}=\frac{\delta_{j} \delta_{t}^{1 / 2}}{C_{\delta} \psi_{0}(0)} \sum_{j=0}^{J} \frac{\Re\left\{X_{n}\left(a_{j}\right)\right\}}{a_{j}^{1 / 2}} .
$$

The factor $\psi_{0}(0)$ removes the energy scaling, while $a_{j}^{1 / 2}$ converts the wavelet transform to an energy density. $\delta_{j}$ and $\delta_{t}$ are the scale averaging coefficient and sampling period. The factor $C_{\delta}$ is a constant (e.g., 0.776 for Morlet wavelet) and comes from the reconstruction of $\delta$ function from its wavelet transform using the wavelet function $\psi_{0}(\eta)$ (e.g., $\pi^{-1 / 4}$ for Morlet wavelet). 


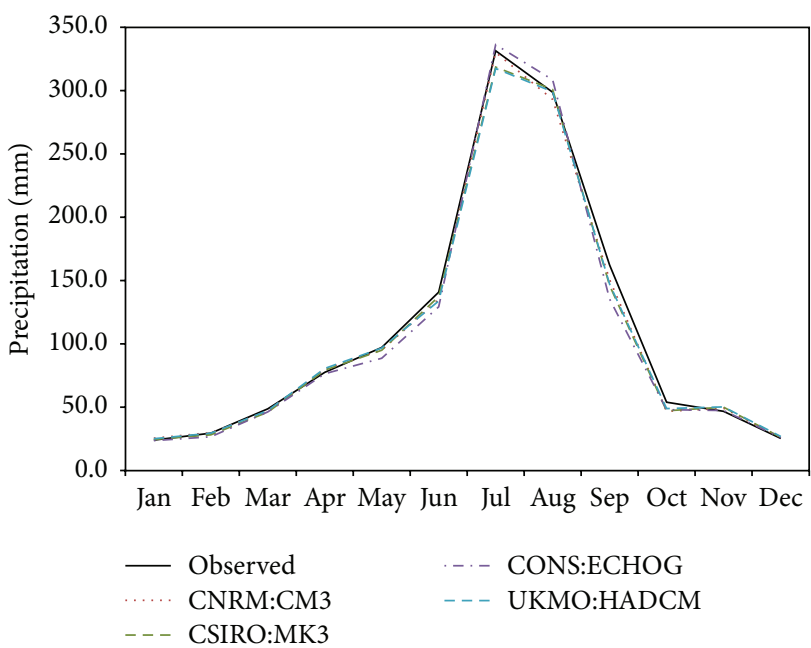

(a) Han River

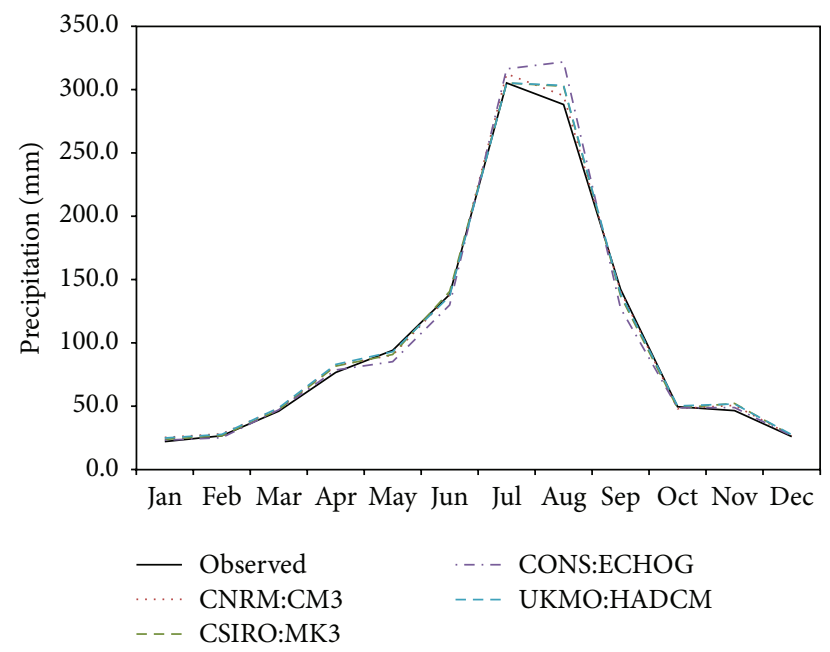

(b) Nakdong River

FIGURE 3: A comparison of the climatological annual cycle between the observed and the simulated data in watersheds of two major rivers for the baseline period (1976-2010).

\section{Results}

4.1. Evaluation of the Downscaled Climate Change Scenario. The scientific concern about impact assessments on hydrologic studies under climate change is uncertainty associated with greenhouse gas concentration projection. Even selecting the relevant greenhouse gas emission scenario may be an issue for future projection, and this could generate various uncertainties [77]. There are four sources of uncertainties in the climate change study. The first issue is the uncertainty associated with the selection of climate change scenario. The second issue is the limited capability of the GCM in terms of reproducing a future climate model based on the selected emission scenario. The third is the results from biases from the statistical downscaling approach. In addition, the bias from the model output must be considered as a limitation of CGMs. Some errors are related to the projection of future hydroclimatic extremes using GCMs [46]. This study used multiple GCMs, which were less biased, to better characterize the uncertainties in investigating the variability of drought under climate change.

First, we try to assure ourselves that the simulated precipitation from the GCMs has similar statistical characteristics to the observed precipitation. In this respect, statistical properties of the simulated data were compared with that of the observed from the Seoul weather station during the historical period. The annual highest precipitation, the annual average precipitation, and the annual lowest precipitation are also compared. The performance of WXGEN was evaluated based on comparison with observed data. For example, statistical hypothesis tests (i.e., $t$-test and $F$-test) were used to determine if mean and variance of the observed and simulated data are significantly different from each other, respectively [78]. It can be seen that the simulated data are significantly close to the observed values, with a $0.05 \%$ significance level.

The results showed that the simulated annual average precipitation and annual lowest precipitation from the four
GCMs are quite similar to the observed ones, while the annual highest precipitation is rather underestimated, suggesting that the simulated future precipitation could lead to a bias around $20 \sim 40 \mathrm{~mm}$ for analysis of drought variability. However, the bias is relatively small compared to the annual precipitation (about $1250 \mathrm{~mm}$ ) such that the effects of bias are rather limited in this study. The underestimation may be due to the underestimation of typhoon-driven extreme rainfalls in the simulation process of the GCMs [79]. Some differences in the simulation of precipitation across the GCMs are identified and these may be because of different climate dynamics, grid resolutions, and physical and parameterization processes [44]. In addition, the seasonal cycle of the GCM is analyzed in terms of the behavior of the monthly periods for five major watersheds. The precipitation climatology is analyzed and compared to observed data during the baseline period (1976-2010) shown in Figure 3. Because of space limitations, we show only the results for Han River and Nakdong River watershed. As displayed in Figure 3, the estimated seasonal cycle is almost identical to the observed one, with small differences in the summer season. Student's $t$-test and $F$-test were also employed to estimate the significant difference of mean and variance; the annual cycle was significantly close to the observed values, with a $0.05 \%$ significance level.

4.2. Spatial Distribution of Trend in Drought. The MK statistics were estimated to identify long-term drought trends at each station. The aforementioned drought index used in this study is the three-month SPI based on observed and GCM precipitation. The entire analysis period spans 19762099 with the first 37 years (historical: 1976-2010) and the remaining period (2011-2099) were forced by the representative concentration pathway scenarios (e.g., RCP 8.5). Four GCMs were downscaled over the South Korean Peninsula domain by a statistical downscaling model. The monthly SPI was rearranged to analyze seasonal drought trends, classified 
as spring (March-May), summer (June-August), autumn (September-November), and winter (December-February). Temporal trends of the SPI are tested at the $\alpha=0.05$ and $\alpha$ $=0.10$ significance level and these trends are then spatially interpolated by using the Thiessen method to better represent spatial distributions of the trends. The spatial distributions of temporal trend in SPI are shown in Figure 4. Note that the positive trend of the SPI times series indicates the wetting (i.e., upward), meaning that occurrence of drought is likely to be less frequent while the negative trend indicates the drying (i.e., downward) trend.

The observed historical SPI shows significant drying trends in all the watersheds during spring and most parts of the lower watershed during winter. In summer, there are no significant drying trends in the upper and lower watersheds $(+0.010 \sim 0.027 /$ year $)$, except for a significant drying trend in a small part of the middle watersheds ( $\leq-0.02 /$ year). In fall, the SPI shows significant wetting trends in most parts of the watersheds, which indicates a predominant increase of precipitation over the South Korean Peninsula. These wetting trends may be related to changes in timing of monthly rainfall where the monthly peak times of most parts of Korea continuously moved backward from early July to early August in recent periods $[13,14]$. In particular, the winter and spring droughts can lead to extreme dry conditions in spring that bring about serious problems during the agricultural planting in South Korea. With regard to this, it would be important to investigate changes in drought conditions in the dry season under climate change.

The simulated temporal evolution of SPI-3 over South Korea reveals a wide spread in the GCMs (Figure 4). In spring, CSIRO-MK3 and UKMO-HADCM show significant drying trends in all watersheds. These patterns are similar to that of the observed historical SPI. On the other hand, CNRM-CM3 and CONS-ECHOG indicate wetting trends in all watersheds at a $10 \%$ significance level. In winter, three GCMs showed significant drying trends in most parts of the watersheds, which will likely result in severe spring droughts. In summer, there are no significant drying trends in most parts of the watersheds, and only CONS:ECOHG showed a significant drying trend. Given the simulated results, the area affected by droughts is likely to increase through the 21st century during the dry season (e.g., spring and winter) which may exacerbate vulnerability to water resources management in South Korea.

4.3. Multiscale Analysis of Drought. A main question in this session is to understand how the low-frequency patterns associated with drought may change in the future under climate change. This question is explored by comparing the global wavelet power (GWP) for the time series. First, we applied the WT to the SPI derived from downscaled monthly precipitation that is spatially averaged for the four GCM data sets for the past period, 1976-2010 (labeled S0), and for three future periods, 2011 to 2040 (labeled S1), 2041 to 2070 (S2), and 2071 to 2100 (S3). Figures 5-6 show the GWP, in which the $x$-axis indicates the cycle (year) and the $y$-axis indicates the wavelet power spectrum. All of the analyses employed the Morlet wavelet and zero padding, and a 95\% confidence limit for the wavelet amplitude corresponding to a null hypothesis of red noise is also illustrated in each of the figures [26]. One generally needs to choose an appropriate background spectrum in order to determine significance levels for wavelet spectra. It has been acknowledged that an appropriate background spectrum for geophysical phenomena is red noise characterized by increasing power with decreasing frequency. If a peak in the wavelet power spectrum is above this background spectrum, then it can be assumed to be a true frequency with a certain percent confidence [26]. Note that the GWP of the SPI for the S0 base scenario is a modeling output derived from the GCMs and not from the observed data. Here, the S0 period in the figure is represented by a red line comprised of circles, the $S 1$ period by a green line, the $S 2$ period by a cyan line, and the S3 period by a pink line of triangles.

In the case of the Han River watershed, the spectra during S1, S2, and S3 decrease in fractional variance attributed to a reduction in the interannual band from 2 years to 8 years in the CSIRO-MK3, UKMO-HADCM, and CNRM-CM3. The only plausible frequency from 30 -year data is about 10 years, given the length of record that is one-third of the time series, so it is not clear that one should directly attach significance to these differences and model them. A strong spectrum is identified around 20 years in CNRM-CM3, CSIRO-MK3, and UKMO-HADCM, which may be related to trends in the SPI series. Given the results of spectrum analysis, interannual variability associated with precipitation will likely decrease. The reduction in the interannual variation can lead to reduction in the long memory and increase in the randomness of the climate system, and this may reduce the usefulness of teleconnection based forecasting systems.

Note that we did not include the results for the Nakdong River watershed because the spectrum structure is almost identical to that of the Han River watershed (not shown in this study). Likewise, the results for the Seomjin River watershed and the Yeongsan River watershed are not included. Instead, the results for the Geum River watershed are only shown as a representative watershed. In the case of the Geum River watershed, significant peaks with a period of 4-8 years are evident in the global power spectrum for the S0 period, indicating the presence of an interannual variation throughout the last several years. As similarly noted in the Han River watershed, the spectra during S1, S2, and S3 decrease in variance in the interannual band from 2 to 8 years in CNRM-CM3, UKMO-HADCM, and CONSECHOG. Again, a strong spectrum is identified around 20 years in most of the GCMs, except for CONS-ECHOG, which may be related to trends. It seems that interannual variability associated with the droughts will likely decrease as indicated in the Han River watershed.

4.4. Frequencies and Severity of Drought. We examined the spatial distribution of the severity and frequency in the dry stages (with $-1.5 \leq$ SPI) in the major river basins. These analyses are conducted through a dry spell analysis that aims to analyze the changes in the frequencies of occurrence and the severity of drought. The dry spell analysis assists in understanding the likelihood of intraseasonal droughts [80]. 


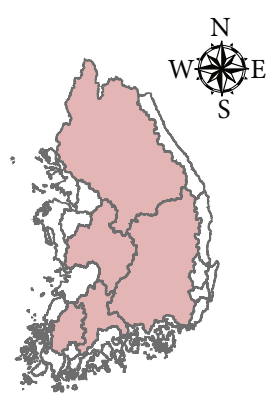

Observed

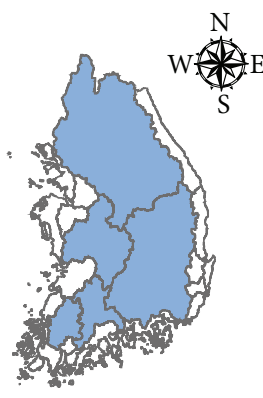

CNRM:CM3

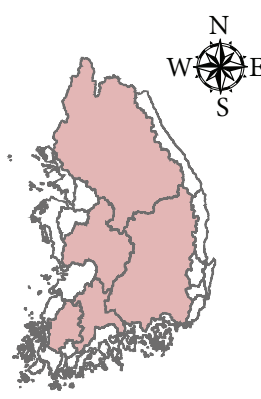

CSIRO:MK3

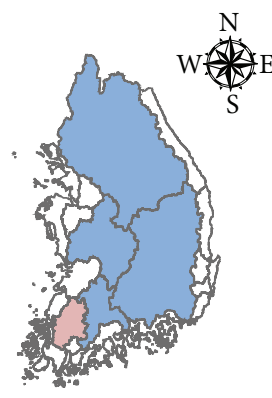

CONS:ECHOG

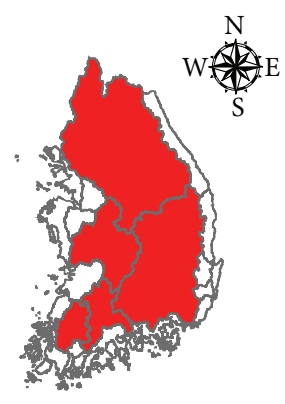

UKMO:HADCM

Wetting (upward) trend that is statistically significant ( $\alpha=0.05$ )

Wetting (upward) trend that is statistically significant $(\alpha=0.1)$

No trend

Drying (downward) trend that is statistically significant $(\alpha=0.1)$

Drying (downward) trend that is statistically significant $(\alpha=0.05)$

(a) Spring

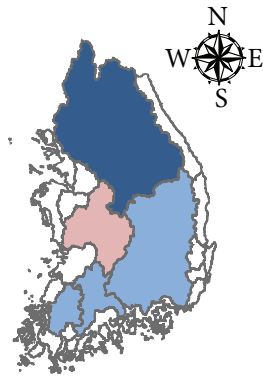

Observed

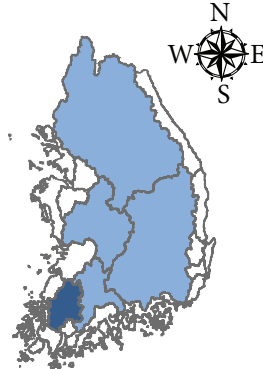

CNRM:CM3

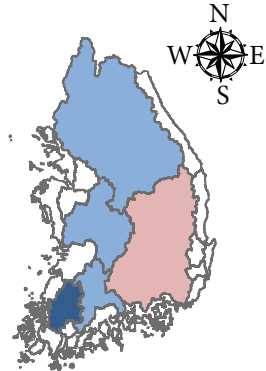

CSIRO:MK3

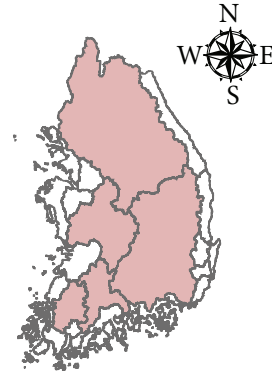

CONS:ECHOG

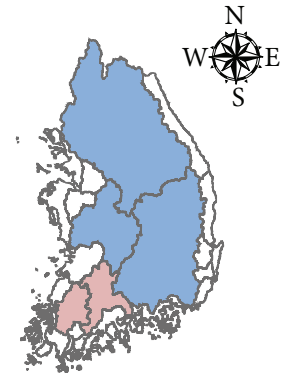

UKMO:HADCM

Wetting (upward) trend that is statistically significant $(\alpha=0.05)$

Wetting (upward) trend that is statistically significant $(\alpha=0.1)$

No trend

Drying (downward) trend that is statistically significant $(\alpha=0.1)$

Drying (downward) trend that is statistically significant $(\alpha=0.05)$

(b) Summer

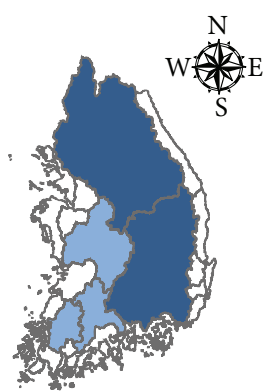

Observed

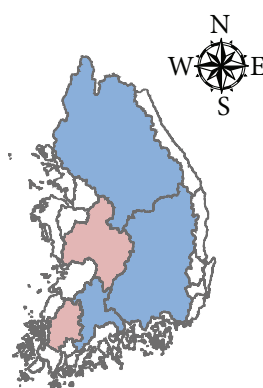

CNRM:CM3

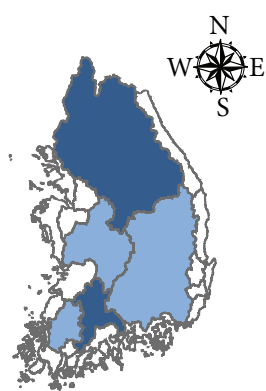

CSIRO:MK3

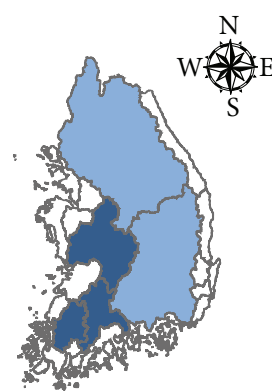

CONS:ECHOG

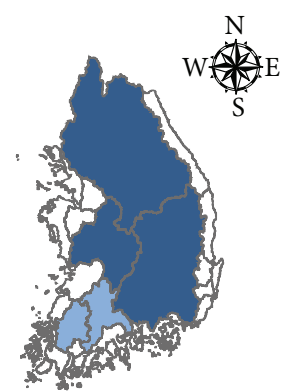

UKMO:HADCM

Wetting (upward) trend that is statistically significant $(\alpha=0.05)$

Wetting (upward) trend that is statistically significant $(\alpha=0.1)$

No trend

Drying (downward) trend that is statistically significant $(\alpha=0.1)$

Drying (downward) trend that is statistically significant $(\alpha=0.05)$

(c) Autumn

FIgURE 4: Continued. 


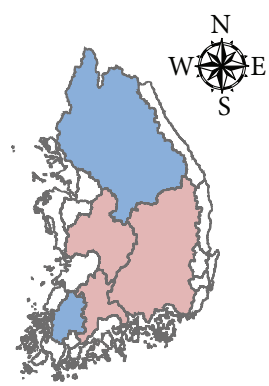

Observed

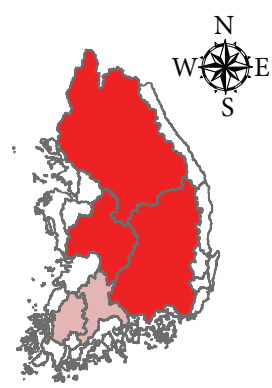

CNRM:CM3

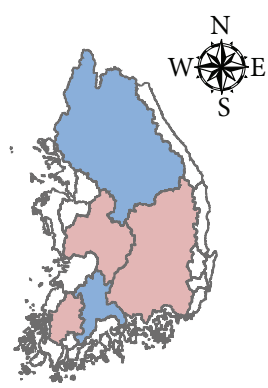

CSIRO:MK3

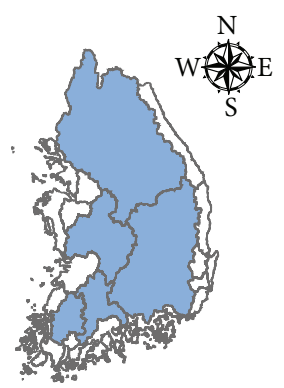

CONS:ECHOG

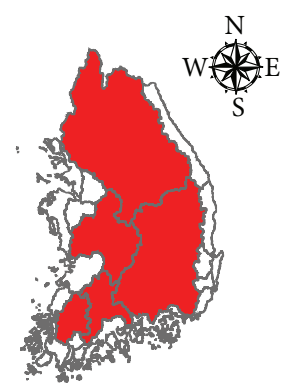

UKMO:HADCM

Wetting (upward) trend that is statistically significant $(\alpha=0.05)$
Wetting (upward) trend that is statistically significant $(\alpha=0.1)$
No trend
Drying (downward) trend that is statistically significant $(\alpha=0.1)$
Drying (downward) trend that is statistically significant $(\alpha=0.05)$

(d) Winter

FIGURE 4: Results of drought trend analysis for each season using the Mann-Kendall test (confidence level $\geq 95 \%$ ).

The analysis period was comprised of two parts: the first, from 1976 to 2010, representing past droughts; the second from 2011 to 2099, speculating on future droughts. Figure 7 shows the spatial distribution of the frequency in severe dry stages with three-month SPI less than -1.5 . Note that the SPI series used here is calculated from a downscaled monthly precipitation that is derived from the hybrid spatiotemporal downscaling model using the four GCMs as inputs. The drought spell analysis using the observed data revealed that the frequency of severe drought was high in the Nakdong River watershed (7.30\%), Seomjin River watershed (7.65\%), and Yeongsan River watershed (7.43\%), which are located in the southern part of the Korean Peninsula. Overall, the severe drought frequency for the future shows a tendency to decrease with time under climate change. In other words, future projection, which averaged the four GCM models, showed that the frequency of severe drought was less than that observed in the past, with 10.68\% (Han River), 26.66\% (Nakdong River), 28.81\% (Geum River), 38.12\% (Seomjin River), and 40.97\% (Yeongsan River), respectively.

Changes in the frequency of severe drought with the four GCMs compared to historical drought data are summarized in Table 5. Among the four GCMs, the CNRM:CM3 showed the lowest frequency of severe drought, while the frequency of the CONS:ECHOG was the highest. In particular, the drought frequency in the Han River basin with the CONS:ECHOG showed $7.26 \%$ for future projections, which is higher than past estimates. The overall frequency of severe drought in the Nakdong River basin was observed to decrease with the four GCMs; however, an increase in the frequency of severe drought in some parts of the Nakdong River basin was identified.

This study evaluated the impact of climate change on drought severity in the region of South Korea. First, the average drought severity analysis, based on the observed SPI, showed that the severity was relatively higher in the
Nakdong River watershed, Seomjin River watershed, and Yeongsan River watershed, in which the frequency of severe drought was higher than for other watersheds. Moreover, it was found that the average severity less than -2.0 was shown in the river basin located in the eastern part of Nakdong River (e.g., Hyeongsan River -2.01, Taehwa River -2.03, and Hoeya/Sooyeong -2.01) and in the southern part of Yeongsan River (-2.01), as summarized in Table 6.

Second, this study investigated the spatial pattern of the average severity in the severe dry stages estimated from three-month SPI less than or equal to -1.5 , as shown in Figure 8 . The average future drought severity less than -2.0 will likely happen in most of the basins under climate change scenarios informed by GCMs, and overall features of the severe drought for the future show a tendency to increase with time under climate change, leading to higher risk in terms of intensified droughts in the Han River basin (8.09\%), Nakdong River basin (5.27\%), Geum River basin (7.85\%), Seomjin River basin (4.91\%), and Yeongsan River basin (3.01\%). The aforementioned Nakdong River basin was an area vulnerable to drought in the past in terms of the frequency and severity of droughts, and these features are likely to be affected by future droughts.

\section{Conclusions}

Climate change is expected to change the hydrological pattern, frequency, and intensity of droughts, leading to a higher number of drought-related disasters, hence the importance of developing a strategy for better assessing the impact of climate change on extremes associated with drought. This effort will allow us to respond proactively by providing policy analysis and advice to policymakers. In this regard, the main objectives of this study were to evaluate the changes in spatial distribution of droughts in terms of frequency and severity under climate change, using IPCC GCM simulations 

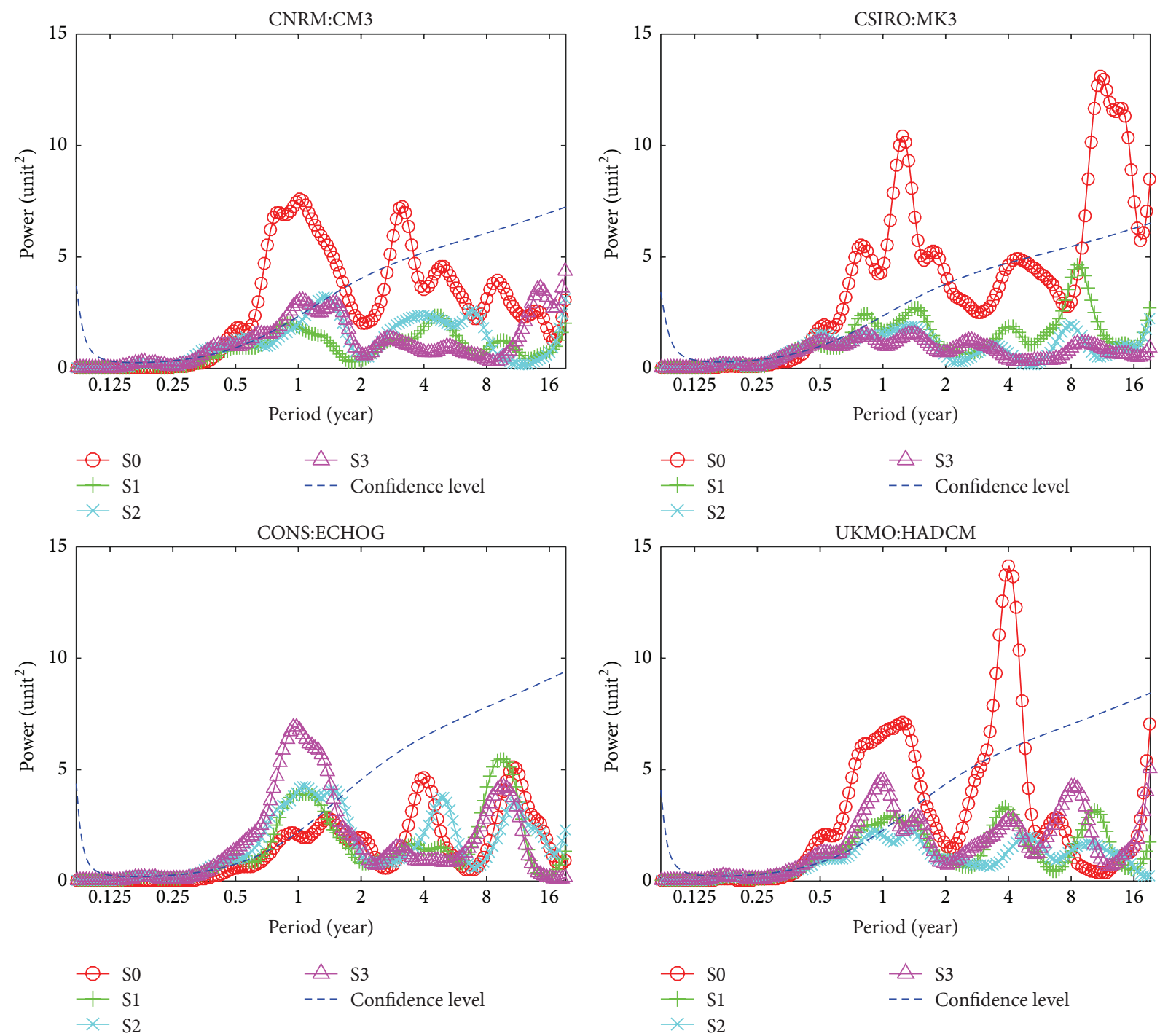

FIGURE 5: A comparison of global wavelet spectra for the Han River watershed (S0: 1976 2010, S1: 2011-2040, S2: 2041-2070, and S3: 20712099). The dashed blue line is the significance for the global wavelet spectrum, assuming the same significance level and background spectrum as in wavelet power spectra. All analyses employed the Morlet wavelet.

in the five major watersheds, Korea. Here, we utilized a Mann-Kendall (MK) trend test and a wavelet transform analysis for the evaluation of the possible changes in drought projections. This study's major contribution is the proposal of a drought pattern analysis to coupling low-frequency issue. An application to the five major watersheds in Korea was illustrated to show how climate change can lead to change in droughts. The following main conclusions are drawn.

(1) The simulated annual average precipitation and annual lowest precipitation from four GCMs of 19762010, equivalent to a baseline period, are quite similar to observed ones. The generated monthly mean and variance of precipitation were significantly close to the observed values, through Student's $t$-test and $F$ test with a $0.05 \%$ significance level. However, some discrepancies in the precipitation during the summer season were identified and these may be due to the exclusion of typhoon-driven extreme events in the simulation process of the GCMs. The temperature was consistently projected to increase under future climate change scenario according four GCMs over South Korea. It was shown that dry season rainfall (e.g., spring and winter) will decline while rainy season rainfall (e.g., summer and fall) will incline over next century. This indicates that change in the seasonality is likely to be enhanced in South Korea under warming climate.

(2) The Mann-Kendall method was adopted to identify drought trends at the five major watersheds. The observed historical SPI showed significant drying trends (i.e., negative trends) in all the watersheds during spring and most parts of the lower watershed during winter. In fall, the SPI showed significant wetting trends (i.e., positive trends) in most parts 

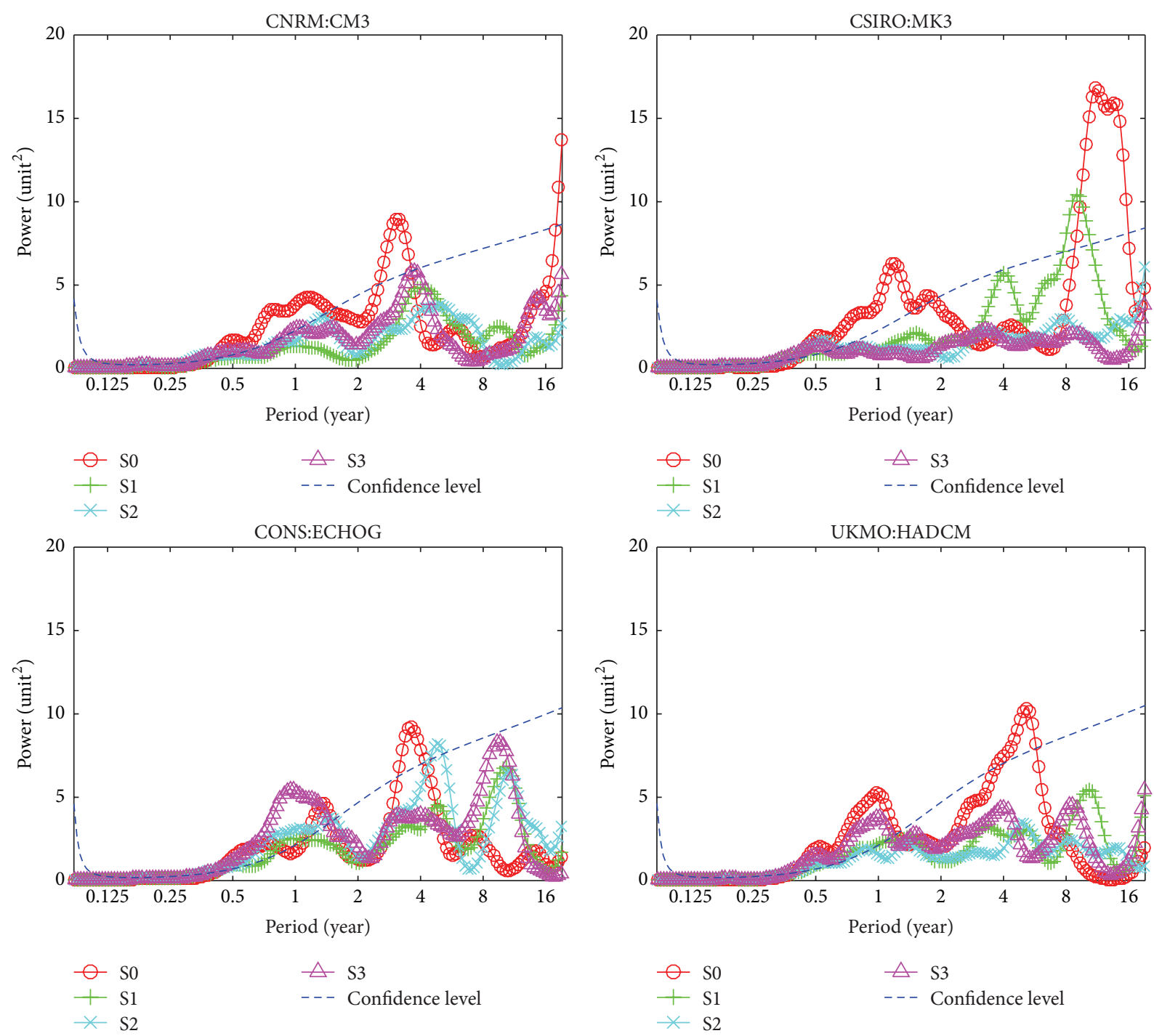

FIGURE 6: A comparison of global wavelet spectra for the Geum River watershed (S0: 1976 2010, S1: 2011-2040, S2: 2041-2070, and S3: 20712099). The dashed blue line is the significance for the global wavelet spectrum, assuming the same significance level and background spectrum as in wavelet power spectra. All analyses employed the Morlet wavelet.

of the watersheds, and these wetting trends may be related to changes in timing of monthly rainfall, with monthly peak times of most parts of Korea continuously moved backward from early July to early August in recent periods. The simulated temporal evolution of SPI during the winter showed significant drying trends in most parts of the watersheds, while the simulated SPI during the spring showed a somewhat different feature in the GCMs. Given the simulated results, overall, a spring drought is likely to be intensified under climate change, and the area affected by the spring drought is likely to increase through the 21st century which may lead to extreme dry conditions during the agricultural planting in South Korea.

(3) This study explored the low-frequency patterns associated with drought by comparing global wavelet power for the time series, with significance test. Significant peaks with a period of $2-8$ years are evident in the global power spectrum in most of the watersheds, indicating the presence of the interannual variation throughout the last several years. Future spectra decreased in the fractional variance attributed to a reduction in the interannual band from 2 to 8 years. The reduction in the interannual variation can lead to reduction in the long memory and increase in the randomness of the climate system, and this may reduce the usefulness of teleconnection based forecasting systems. The results are consistent with others indicating that the randomness in the climate system will increase under a warmer climate [81-83].

(4) Finally, the changes in the frequency and the severity under climate change were evaluated through the drought spell analyses. The results showed that the 


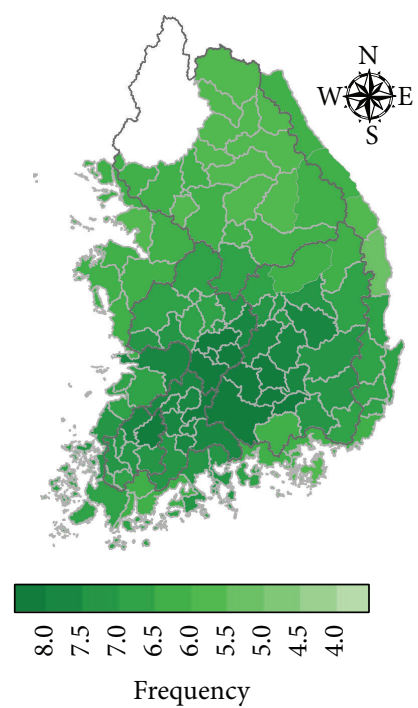

(a) Observed

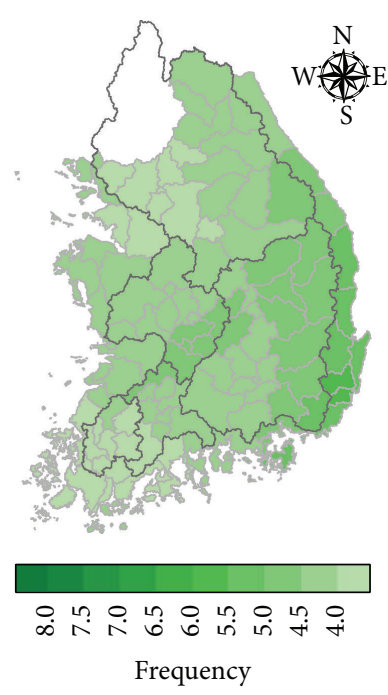

(b) CNRM:CM3

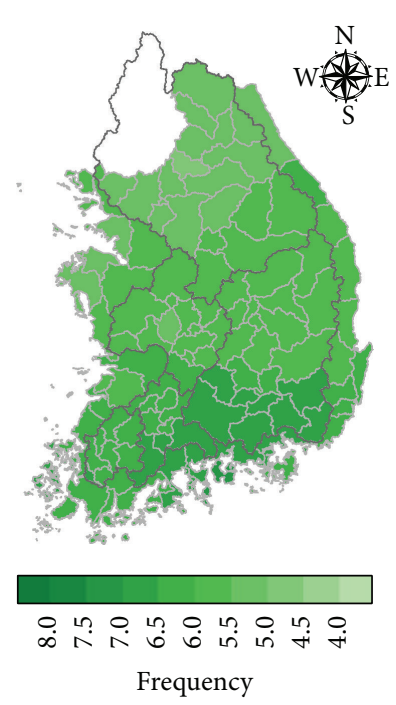

(e) UKMO:HADCM

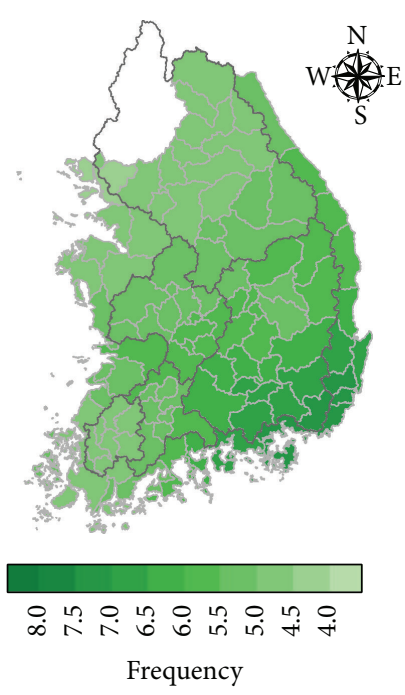

(c) CSIRO:MK3

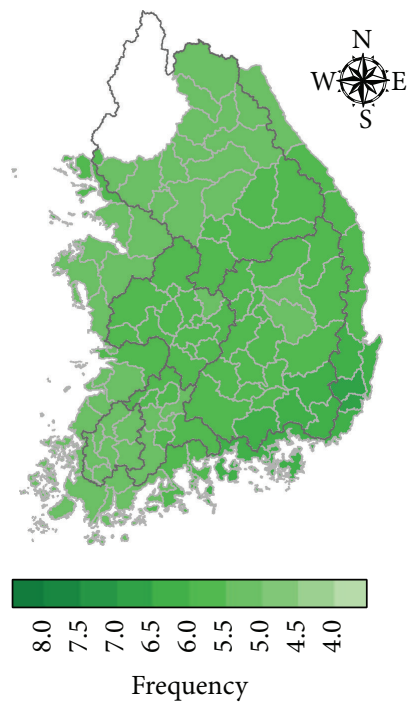

(f) MME average

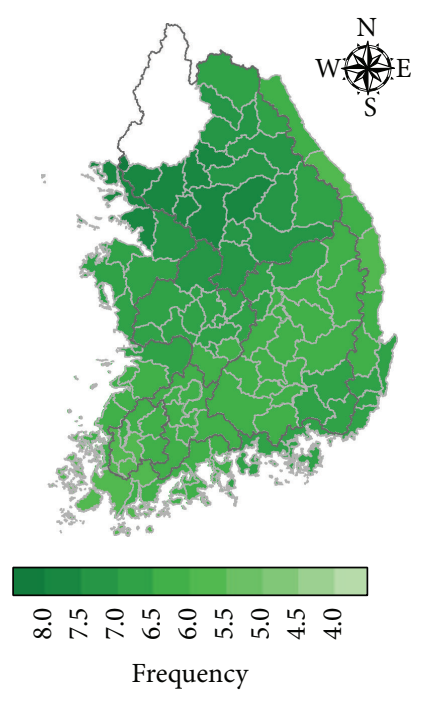

(d) CONS:ECHOG

FIgURE 7: The spatial distribution of the frequency in severe dry stages with three-month SPI less than or equal to -1.5 for past and future climate change projections. (a) Observed frequency of severe drought for the period 1976-2010 and (b-f) projected frequency of severe drought by each GCM and MME average for the period 2011-2099 for the climate change scenario. Note that the SPI series is calculated from a downscaled monthly precipitation using the four GCMs as inputs.

projected SPI was found to decrease in frequency for mild and moderate drought cases over time. However, in cases of severe droughts less than -2.0 , the frequency was found to increase slightly over time in most of the watersheds under climate change. Overall features of drought conditions in the future showed a tendency to decrease in frequency and increase in severity with time under climate change, leading to higher risk in terms of intensified damage of drought.

This study investigated potential changes in the characteristics of drought using multimodel simulations. Readers should be aware of some issues regarding the uncertainty and assumptions of models. Indeed, the uncertainty of scenarios used herein is an essential influence on the projected changes in drought. Despite using cutting-edge climate simulations of IPCC climate model, it is still unable to reproduce historical extremes (droughts and floods) associated with natural climate variability. The importance of climate model resolution to improving reproduction of climate dynamics over a large area in East Asia has been reported (e.g., [84, 85]). Hence, dynamical downscaling system using regional climate models (RCMs) would be useful for reliable climate change studies in South Korea. However, a high resolution regional climate model ensemble system for South Korea is not available. 
TABLE 5: Changes in the frequency in severe dry stages with three-month SPI less than -1.5 for past and future climate change projections. Observed frequency of severe drought for the period 1976-2010 and projected change in frequency of severe drought by each GCM and MME average for the period 2011-2099 for the climate change scenario. Difference is a percentage change in drought frequency between past and future periods, and positive value indicates increasing trend and vice versa. Note that the SPI series is calculated from a downscaled monthly precipitation using the four GCMs as inputs.

\begin{tabular}{|c|c|c|c|c|c|c|c|c|}
\hline Name & ID & Observed & CNRM & CSIRO & ECHOG & HADCM & MME & Diff (\%) \\
\hline Han River & 10 & 6.00 & 4.13 & 4.93 & 7.26 & 5.38 & 5.42 & -10.68 \\
\hline Anseong Stream & 11 & 6.10 & 3.99 & 4.90 & 7.35 & 5.54 & 5.44 & -12.14 \\
\hline West of Han River & 12 & 6.04 & 4.00 & 4.60 & 7.68 & 5.67 & 5.48 & -10.18 \\
\hline East of Han River & 13 & 6.17 & 4.71 & 5.52 & 6.00 & 5.71 & 5.48 & -12.49 \\
\hline Nakdong River & 20 & 7.30 & 4.56 & 6.02 & 6.36 & 6.12 & 5.76 & -26.66 \\
\hline East of Nakdong River & 24 & 6.10 & 5.18 & 6.15 & 6.13 & 5.82 & 5.82 & -4.85 \\
\hline South of Nakdong River & 25 & 6.34 & 4.67 & 6.99 & 6.66 & 6.68 & 6.25 & -1.39 \\
\hline Hyeongsan River & 21 & 6.82 & 5.20 & 6.50 & 6.50 & 5.99 & 6.05 & -12.75 \\
\hline Taehwa River & 22 & 6.69 & 5.51 & 7.38 & 6.89 & 6.23 & 6.50 & -2.97 \\
\hline Hoeya, Sooyeong & 23 & 6.52 & 5.46 & 7.24 & 6.94 & 6.32 & 6.49 & -0.52 \\
\hline Geum River & 30 & 7.19 & 4.35 & 5.45 & 6.81 & 5.72 & 5.58 & -28.81 \\
\hline Sapgyo Stream & 31 & 6.41 & 4.33 & 4.95 & 6.89 & 5.59 & 5.44 & -17.87 \\
\hline West of Geum River & 32 & 6.18 & 4.38 & 4.79 & 6.81 & 5.47 & 5.36 & -15.19 \\
\hline Mangyeong, Dongjin & 33 & 7.33 & 4.37 & 5.42 & 6.44 & 5.99 & 5.55 & -31.98 \\
\hline Seomjin River & 40 & 7.65 & 4.16 & 5.38 & 6.27 & 6.35 & 5.54 & -38.12 \\
\hline South of Seomjin River & 41 & 6.86 & 4.01 & 5.65 & 6.21 & 6.58 & 5.61 & -22.21 \\
\hline Yeongsan River & 50 & 7.43 & 3.92 & 4.83 & 6.03 & 6.31 & 5.27 & -40.97 \\
\hline Tamjin River & 51 & 6.02 & 3.75 & 4.88 & 5.99 & 6.40 & 5.26 & -14.59 \\
\hline South of Yeongsan River & 52 & 6.78 & 3.93 & 4.96 & 5.91 & 6.19 & 5.25 & -29.16 \\
\hline West of Yeongsan River & 53 & 7.04 & 3.97 & 5.04 & 6.09 & 6.32 & 5.36 & -31.51 \\
\hline
\end{tabular}

TABLE 6: Changes in the severity of drought in severe dry stages with three-month SPI less than -1.5 for past and future climate change projections. Observed severity of drought for the period 1976-2010 and projected change in severity of drought by each GCM and MME average for the period 2011-2099 for the climate change scenario. Difference is a percentage change in severity of drought between past and future periods, and positive value indicates increasing trend and vice versa. Note that the SPI series is calculated from a downscaled monthly precipitation using the four GCMs as inputs.

\begin{tabular}{|c|c|c|c|c|c|c|c|c|}
\hline Name & ID & Observed & CNRM & CSIRO & ECHOG & HADCM & MME & Diff $(\%)$ \\
\hline Han River & 10 & -1.91 & -2.08 & -2.00 & -2.19 & -1.98 & -2.06 & 8.09 \\
\hline Anseong Stream & 11 & -1.92 & -2.09 & -2.01 & -2.21 & -1.95 & -2.07 & 7.75 \\
\hline West of Han River & 12 & -1.89 & -2.11 & -2.02 & -2.20 & -1.98 & -2.08 & 9.84 \\
\hline East of Han River & 13 & -1.87 & -2.11 & -1.99 & -2.14 & -2.03 & -2.07 & 10.63 \\
\hline Nakdong River & 20 & -1.98 & -2.04 & -1.98 & -2.22 & -2.09 & -2.08 & 5.27 \\
\hline East of Nakdong River & 24 & -1.96 & -2.09 & -1.95 & -2.15 & -2.15 & -2.09 & 6.40 \\
\hline South of Nakdong River & 25 & -1.98 & -2.06 & -1.99 & -2.19 & -2.09 & -2.08 & 5.07 \\
\hline Hyeongsan River & 21 & -2.01 & -2.08 & -1.96 & -2.18 & -2.16 & -2.10 & 4.30 \\
\hline Taehwa River & 22 & -2.03 & -2.08 & -1.95 & -2.16 & -2.18 & -2.09 & 3.22 \\
\hline Hoeya/Sooyeong & 23 & -2.01 & -2.08 & -1.97 & -2.18 & -2.17 & -2.10 & 4.38 \\
\hline Geum River & 30 & -1.90 & -1.98 & -1.97 & -2.24 & -2.00 & -2.05 & 7.85 \\
\hline Sapgyo Stream & 31 & -1.90 & -2.05 & -2.02 & -2.22 & -1.95 & -2.06 & 8.56 \\
\hline West of Geum River & 32 & -1.90 & -2.05 & -2.03 & -2.23 & -1.96 & -2.07 & 9.06 \\
\hline Mangyeong, Dongjin & 33 & -1.93 & -1.96 & -1.95 & -2.28 & -1.99 & -2.04 & 6.14 \\
\hline Seomjin River & 40 & -1.95 & -1.93 & -1.98 & -2.22 & -2.03 & -2.04 & 4.91 \\
\hline South of Seomjin River & 41 & -1.95 & -2.00 & -2.00 & -2.16 & -2.06 & -2.05 & 5.11 \\
\hline Yeongsan River & 50 & -1.97 & -1.92 & -1.98 & -2.20 & -2.00 & -2.03 & 3.01 \\
\hline Tamjin River & 51 & -1.99 & -1.98 & -2.01 & -2.15 & -2.05 & -2.05 & 3.07 \\
\hline South of Yeongsan River & 52 & -2.01 & -1.98 & -2.00 & -2.15 & -2.04 & -2.04 & 1.79 \\
\hline West of Yeongsan River & 53 & -1.99 & -1.95 & -1.97 & -2.21 & -1.99 & -2.03 & 2.13 \\
\hline
\end{tabular}




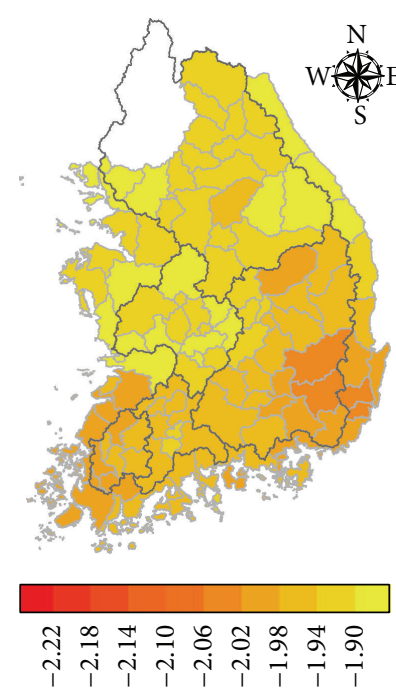

SPI

(a) Observed

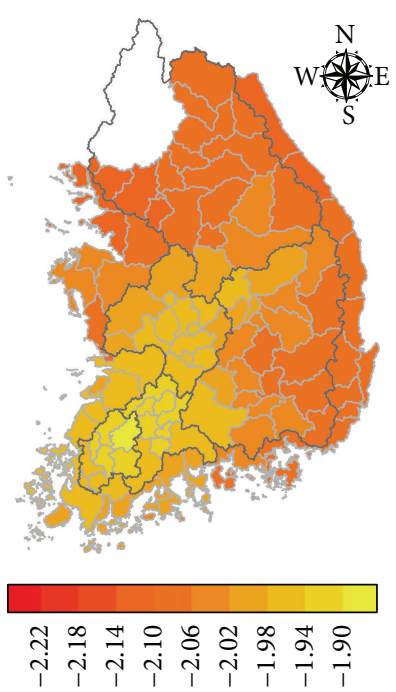

SPI

(b) CNRM:CM3

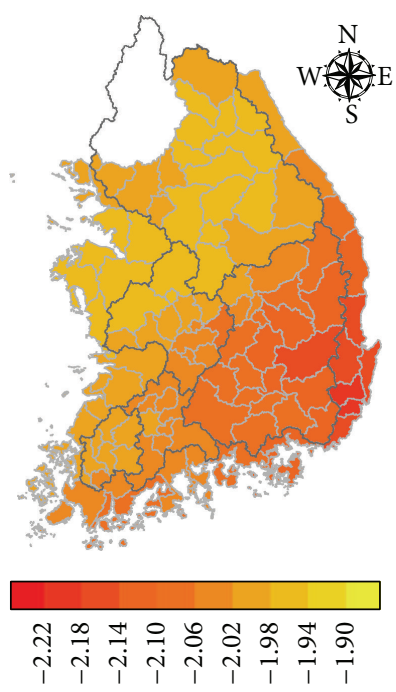

SPI

(e) UKMO:HADCM

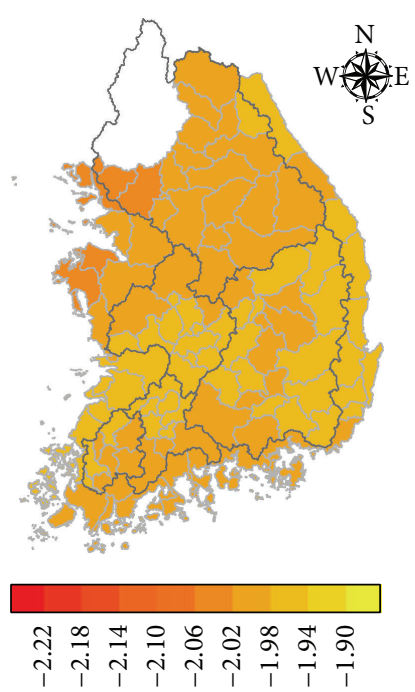

SPI

(c) CSIRO:MK3

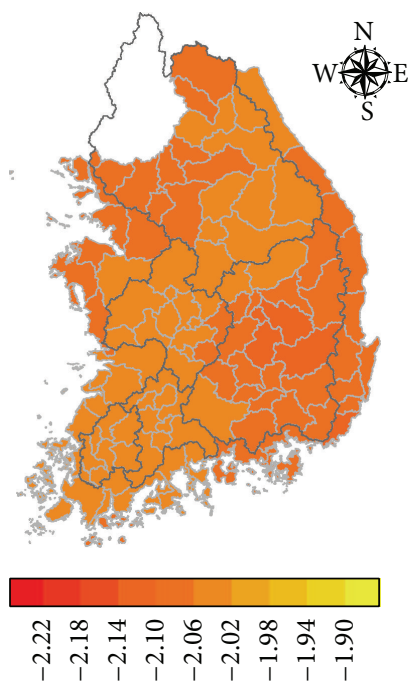

SPI

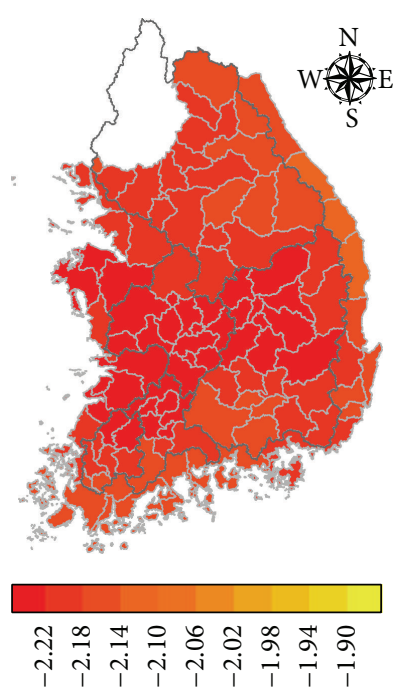

SPI

(d) CONS:ECHOG

FIGURE 8: The spatial distribution of the severity of drought with three-month SPI less than or equal to -1.5 for past and future climate change projections. (a) Observed severity of drought for the period 1976-2010 and (b-f) projected severity of drought by each GCM and MME average for the period 2011-2099 for the climate change scenario. Note that the SPI series is calculated from a downscaled monthly precipitation using the four GCMs as inputs.

If RCM ensemble simulation is utilized, the uncertainties in extreme climate projection are expected to be reduced. Our ongoing research focuses on using the RCM to better understand future drought for water resources management.

\section{Competing Interests}

The authors declare that they have no competing interests.

\section{Acknowledgments}

This research was supported by a Grant (15AWMP-B07962502) from Water Management Research Program funded by
Ministry of Land, Infrastructure and Transport of Korean government.

\section{References}

[1] H.-H. Kwon, A. F. Khalil, and T. Siegfried, "Analysis of extreme summer rainfall using climate teleconnections and typhoon characteristics in South Korea," Journal of the American Water Resources Association, vol. 44, no. 2, pp. 436-448, 2008.

[2] H.-H. Kwon, C. Brown, and U. Lall, "Climate informed flood frequency analysis and prediction in Montana using hierarchical Bayesian modeling," Geophysical Research Letters, vol. 35, no. 5, Article ID L05404, 2008. 
[3] H.-H. Kwon, B. Sivakumar, Y.-I. Moon, and B.-S. Kim, "Assessment of change in design flood frequency under climate change using a multivariate downscaling model and a precipitationrunoff model," Stochastic Environmental Research and Risk Assessment, vol. 25, no. 4, pp. 567-581, 2011.

[4] IPCC, Climate Change 2007: The Physical Science Basis. Working Group I Contribution to the Fourth Assessment Report of the Intergovernmental Panel on Climate Change, Summary for Policymakers, Cambridge University Press, Cambridge, UK, 2007.

[5] S. Jain and U. Lall, "Floods in a changing climate: does the past represent the future?" Water Resources Research, vol. 37, no. 12, pp. 3193-3205, 2001.

[6] J. Yoo, H.-H. Kwon, T.-W. Kim, and J.-H. Ahn, "Drought frequency analysis using cluster analysis and bivariate probability distribution," Journal of Hydrology, vol. 420-421, pp. 102-111, 2012.

[7] M. Hoerling, J. Eischeid, J. Perlwitz, X. Quan, T. Zhang, and P. Pegion, "On the increased frequency of mediterranean drought," Journal of Climate, vol. 25, no. 6, pp. 2146-2161, 2012.

[8] B. Nandintsetseg and M. Shinoda, "Assessment of drought frequency, duration, and severity and its impact on pasture production in Mongolia," Natural Hazards, vol. 66, no. 2, pp. 995-1008, 2013.

[9] M. Zhang, J. He, B. Wang et al., "Extreme drought changes in Southwest China from 1960 to 2009," Journal of Geographical Sciences, vol. 23, no. 1, pp. 3-16, 2013.

[10] J. Spinoni, G. Naumann, H. Carrao, P. Barbosa, and J. Vogt, "World drought frequency, duration, and severity for 19512010," International Journal of Climatology, vol. 34, no. 8, pp. 2792-2804, 2014.

[11] J. R. Olsen, J. R. Stedinger, N. C. Matalas, and E. Z. Stakhiv, "Climate variability and flood frequency estimation for the Upper Mississippi and Lower Missouri Rivers," Journal of the American Water Resources Association, vol. 35, no. 6, pp. 15091523, 1999.

[12] A. Sankarasubramanian and U. Lall, "Flood quantiles in a changing climate: seasonal forecasts and causal relations," Water Resources Research, vol. 39, no. 5, 2003.

[13] J. H. Lee, J. W. Seo, and C. J. Kim, "Analysis on trends, periodicities and frequencies of korean drought using drought indices," Journal of Korea Water Resources Association, vol. 45, no. 1, pp. 75-89, 2012 (Korean).

[14] J.-J. Lee, H.-H. Kwon, and T.-W. Kim, "Spatio-temporal analysis of extreme precipitation regimes across South Korea and its application to regionalization," Journal of Hydro-Environment Research, vol. 6, no. 2, pp. 101-110, 2012.

[15] H. H. Kwon and Y. I. Moon, "Analysis of hydrologic time series using wavelet transform," Journal of Korea Water Resources Association, vol. 38, no. 6, pp. 439-448, 2005 (Korean).

[16] H. H. Kwon and Y. I. Moon, "Correlation analysis between palmer drought severity index (PDSI) and ENSO indices," Journal of Korean Society Civil Engineering, vol. 25, no. 5, pp. 355-358, 2005 (Korean).

[17] S. Kim, "Wavelet analysis of precipitation variability in northern California, U.S.A.," Journal of Korean Society Civil Engineering, vol. 8, no. 4, pp. 471-477, 2004.

[18] Y. N. Yoon, J. H. Ahn, and D. R. Lee, "A study of drought severity index using palmer method," Journal of Korea Water Resources Association, vol. 30, no. 5, pp. 317-326, 1997 (Korean).

[19] C. J. Kim, J. W. Seo, M. J. Park, J. S. Shin, and J. H. Lee, "Climate change and future drought occurrence of Korean," in
Proceeding of the Korea Society of Hazard Mitigation, vol. 205, 2011 (Korean).

[20] G. Choi, W.-T. Kwon, K.-O. Boo, and Y.-M. Cha, "Recent spatial and temporal changes in means and extreme events of temperature and precipitation across the Republic of Korea," Journal of the Korean Geographical Society, vol. 43, no. 5, pp. 681-700, 2008.

[21] K.-O. Boo, W.-T. Kwon, J.-H. Oh, and H.-J. Baek, "Response of global warming on regional climate change over Korea: an experiment with the MM5 model," Geophysical Research Letters, vol. 31, no. 21, Article ID L21206, 2004.

[22] W. A. Landman and S. J. Mason, "Change in the association between Indian Ocean sea-surface temperatures and summer rainfall over South Africa and Namibia," International Journal of Climatology, vol. 19, no. 13, pp. 1477-1492, 1999.

[23] W. A. Landman, S. J. Mason, P. D. Tyson, and W. J. Tennant, "Retro-active skill of multi-tiered forecasts of summer rainfall over southern Africa," International Journal of Climatology, vol. 21, no. 1, pp. 1-19, 2001.

[24] H.-H. Kwon, U. Lall, and A. F. Khalil, "Stochastic simulation model for nonstationary time series using an autoregressive wavelet decomposition: applications to rainfall and temperature," Water Resources Research, vol. 43, no. 5, Article ID W05407, 2007.

[25] N. E. Huang, Z. Shen, S. R. Long et al., "The empirical mode decomposition and the Hilbert spectrum for nonlinear and non-stationary time series analysis," Proceedings of the Royal Society of London-Series A: Mathematical Physical and Engineering Sciences, vol. 454, no. 1971, pp. 903-995, 1998.

[26] C. Torrence and G. P. Compo, "A practical guide to wavelet analysis," Bulletin of the American Meteorological Society, vol. 79, no. 1, pp. 61-78, 1998.

[27] A. Grinsted, J. C. Moore, and S. Jevrejeva, "Application of the cross wavelet transform and wavelet coherence to geophysical times series," Nonlinear Processes in Geophysics, vol. 11, no. 5-6, pp. 561-566, 2004.

[28] R. Essery, "Seasonal snow cover and climate change in the Hadley Centre GCM," Annals of Glaciology, vol. 25, pp. 362-266, 1997.

[29] K. W. Dixon and J. R. Lanzante, "Global mean surface air temperature and North Atlantic overturning in a suite of coupled GCM climate change experiments," Geophysical Research Letters, vol. 26, no. 13, Article ID 1999GL900382, pp. 1885-1888, 1999.

[30] F. Vitart and T. N. Stockdale, "Seasonal forecasting of tropical storms using coupled GCM integrations," Monthly Weather Review, vol. 129, no. 10, pp. 2521-2537, 2001.

[31] D. P. Rowell, "Assessing potential seasonal predictability with an ensemble of multidecadal GCM simulations," Journal of Climate, vol. 11, no. 2, pp. 109-120, 1998.

[32] A. W. Robertson, S. Kirshner, and P. Smyth, "Downscaling of daily rainfall occurrence over Northeast Brazil using a hidden Markov model," Journal of Climate, vol. 17, no. 22, pp. 44074424, 2004.

[33] A. W. Robertson, U. Lall, S. E. Zebiak, and L. Goddard, "Improved combination of multiple atmospheric GCM ensembles for seasonal prediction," Monthly Weather Review, vol. 132, no. 12, pp. 2732-2744, 2004.

[34] A. F. Khalil, H.-H. Kwon, U. Lall, and Y. H. Kaheil, "Predictive downscaling based on non-homogeneous hidden Markov models," Hydrological Sciences Journal, vol. 55, no. 3, pp. 333-350, 2010. 
[35] J. M. Mendes, K. F. Turkman, and J. Corte-Real, "A Bayesian hierarchical model for local precipitation by downscaling largescale atmospheric circulation patterns," Environmetrics, vol. 17, no. 7, pp. 721-738, 2006.

[36] F. Giorgi and L. O. Mearns, "Approaches to the simulation of regional climate change: a review," Reviews of Geophysics, vol. 29, no. 2, pp. 191-216, 1991.

[37] J. Murphy, "An evaluation of statistical and dynamical techniques for downscaling local climate," Journal of Climate, vol. 12, no. 8, pp. 2256-2284, 1999.

[38] J. H. Christensen, F. Boberg, O. B. Christensen, and P. LucasPicher, "On the need for bias correction of regional climate change projections of temperature and precipitation," Geophysical Research Letters, vol. 35, no. 20, Article ID L20709, 2008.

[39] D. Maraun, F. Wetterhall, A. M. Ireson et al., "Precipitation downscaling under climate change: recent developments to bridge the gap between dynamical models and the end user," Reviews of Geophysics, vol. 48, no. 3, Article ID RG3003, 2010.

[40] C. Teutschbein and J. Seibert, "Bias correction of regional climate model simulations for hydrological climate-change impact studies: review and evaluation of different methods," Journal of Hydrology, vol. 456-457, pp. 12-29, 2012.

[41] J. A. Winkler, G. S. Guentchev, M. Liszewska, Perdinan, and P.-N. Tan, "Climate scenario development and applications for local/regional climate change impact assessments: an overview for the non-climate scientist-part II: considerations when using climate change scenarios," Geography Compass, vol. 5, no. 6, pp. 301-328, 2011.

[42] J. A. Winkler, G. S. Guentchev, S. Perdinan et al., "Climate scenario development and applications for local/regional climate change impact assessments: an overview for the nonclimate scientist-part I: scenario development using downscaling methods climate scenario development and applications I," Geography Compass, vol. 5, no. 6, pp. 275-300, 2011.

[43] J. H. Christensen, B. Hewitson, A. Busuioc et al., "Regional climate projections," in Climate Change 2007. The Physical Science Basis. Contribution of WGI to the IPCC AR4, S. Solomon, D. Qin, M. Manning et al., Eds., Cambridge University Press, New York, NY, USA, 2007.

[44] E.-S. Im, I.-W. Jung, H. Chang, D.-H. Bae, and W.-T. Kwon, "Hydroclimatological response to dynamically downscaled climate change simulations for Korean basins," Climatic Change, vol. 100, no. 3, pp. 485-508, 2010.

[45] A. W. Wood, L. R. Leung, V. Sridhar, and D. P. Lettenmaier, "Hydrologic implications of dynamical and statistical approaches to downscaling climate model outputs," Climatic Change, vol. 62, no. 1-3, pp. 189-216, 2004.

[46] J. H. Lee and C. J. Kim, "A multimodel assessment of the climate change effect on the drought severity-duration-frequency relationship," Hydrological Processes, vol. 27, no. 19, pp. 2800-2813, 2013.

[47] K.-Y. Kim and G. R. North, "EOFs of harmonizable cyclostationary processes," Journal of the Atmospheric Sciences, vol. 54, no. 19, pp. 2416-2427, 1997.

[48] Y.-K. Lim, D. W. Shin, S. Cocke et al., "Dynamically and statistically downscaled seasonal simulations of maximum surface air temperature over the southeastern United States," Journal of Geophysical Research Atmospheres, vol. 112, no. 24, Article ID D24, 2007.

[49] A. N. Sharpley and J. R. Williams, "Erosion/productivity impact calculator: 1. Model documentation," Technical Bulletin 1768, US Department of Agriculture, Washington, DC, USA, 1990.
[50] D. H. Bae, I. W. Jung, B. J. Lee, and M. H. Lee, "Future Korean water resources projection considering uncertainty of GCMs and hydrological models," Journal of Korea Water Resources Association, vol. 44, no. 5, pp. 389-406, 2011 (Korean).

[51] D.-H. Bae, I.-W. Jung, and D. P. Lettenmaier, "Hydrologic uncertainties in climate change from IPCC AR4 GCM simulations of the Chungju basin, Korea," Journal of Hydrology, vol. 401, no. 1-2, pp. 90-105, 2011.

[52] C. W. Richardson, "Stochastic simulation of daily precipitation, temperature, and solar radiation," Water Resources Research, vol. 17, no. 1, pp. 182-190, 1981.

[53] I. W. Jung, D. H. Bae, and B. J. Lee, "Possible change in Korean streamflow seasonality based on multi-model climate projections," Hydrological Processes, vol. 27, no. 7, pp. 1033-1045, 2013.

[54] S. L. Neitsch, J. R. Williams, J. G. Arnold, and J. R. Kiniry, Soil and Water Assessment Tool Theoretical Documentation Version 2009, Texas Water Resources Institute, College Station, Tex, USA, 2011.

[55] J. Schuol and K. C. Abbaspour, "Using monthly weather statistics to generate daily data in a SWAT model application to West Africa," Ecological Modelling, vol. 201, no. 3-4, pp. 301-311, 2007.

[56] B. Dixon and J. Earls, "Effects of urbanization on streamflow using SWAT with real and simulated meteorological data," Applied Geography, vol. 35, no. 1-2, pp. 174-190, 2012.

[57] J. Schuol, K. C. Abbaspour, R. Srinivasan, and H. Yang, "Estimation of freshwater availability in the West African sub-continent using the SWAT hydrologic model," Journal of Hydrology, vol. 352, no. 1-2, pp. 30-49, 2008.

[58] D. L. Ficklin, Y. Luo, E. Luedeling, and M. Zhang, "Climate change sensitivity assessment of a highly agricultural watershed using SWAT,' Journal of Hydrology, vol. 374, no. 1-2, pp. 16-29, 2009.

[59] Y. Wu, S. Liu, and O. I. Abdul-Aziz, "Hydrological effects of the increased $\mathrm{CO}_{2}$ and climate change in the Upper Mississippi River Basin using a modified SWAT,' Climatic Change, vol. 110, no. 3-4, pp. 977-1003, 2012.

[60] P. B. Parajuli, "Assessing sensitivity of hydrologic responses to climate change from forested watershed in Mississippi," Hydrological Processes, vol. 24, no. 26, pp. 3785-3797, 2010.

[61] H. N. Hayhoe, "Relationship between weather variables in observed and WXGEN generated data series," Agricultural and Forest Meteorology, vol. 90, no. 3, pp. 203-214, 1998.

[62] T. B. McKee, N. J. Doesken, and J. Kleist, "The relationship of drought frequency and duration to time scales," in Proceedings of the 8th Conference on Applied Climatology, pp. 179-184, Anaheim, Calif, USA, January 1993.

[63] T. B. McKee, N. J. Doesken, and J. Kleist, "Drought monitoring with multiple time scales," in Proceedings of the 9th Conference on Applied Climatology, pp. 233-236, Dallas, Tex, USA, January 1995.

[64] H. C. Thom, "A note on the gamma distribution," Monthly Weather Review, vol. 86, no. 4, pp. 117-122, 1958.

[65] H. C. S. Thom, "Some methods of climatological analysis. WMO N. 199," Technical Note N. 81, World Meteorological Organization, Ginevra, Switzerland, 1966.

[66] H. A. Panofsky and G. W. Brier, Some Applications of Statistics to Meteorology, Pennsylvania State University, University Park, State College, Pa, USA, 1958. 
[67] H. B. Mann, "Nonparametric tests against trend," Econometrica, vol. 13, pp. 245-259, 1945.

[68] M. G. Kendall, Rank Correlation Methods, Charles Griffin, London, UK, 1975.

[69] R. O. Gilbert, Statistical Methods for Environmental Pollution Monitoring, John Wiley \& Sons, New York, NY, USA, 1987.

[70] J. D. Gibbons, Handbook of Statistical Methods for Engineers and Scientists, McGraw-Hill Education, New York, NY, USA, 1990.

[71] R. W. Katz and B. G. Brown, "Extreme events in a changing climate: variability is more important than averages," Climatic Change, vol. 21, no. 3, pp. 289-302, 1992.

[72] G. A. Meehl, T. Karl, D. R. Easterling et al., "An introduction to trends in extreme weather and climate events: observations, socioeconomic impacts, terrestrial ecological impacts, and model projections," Bulletin of the American Meteorological Society, vol. 81, no. 3, pp. 413-416, 2000.

[73] H.-H. Kwon, U. Lall, Y.-I. Moon, A. F. Khalil, and H. Ahn, "Episodic interannual climate oscillations and their influence on seasonal rainfall in the Everglades National Park," Water Resources Research, vol. 42, no. 11, 2006.

[74] C. K. Chui, An Introduction to Wavelets, Wavelet Analysis and Its Application, vol. 1, Academic Press, Boston, Mass, USA, 1992.

[75] E. Foufoula-Georgiou and P. Kumar, Wavelet in Geophysics, Academic Press, London, UK, 1994.

[76] G. Kaiser, A Friendly Guide to Wavelets, Birkhäuser, Boston, Mass, USA, 1994.

[77] E. P. Maurer, "Uncertainty in hydrologic impacts of climate change in the Sierra Nevada, California, under two emissions scenarios," Climatic Change, vol. 82, no. 3-4, pp. 309-325, 2007.

[78] M. A. Semenov and E. M. Barrow, "Use of a stochastic weather generator in the development of climate change scenarios," Climatic Change, vol. 35, no. 4, pp. 397-414, 1997.

[79] C. J. Kim, M. J. Park, and J. H. Lee, "Analysis of climate change impacts on the spatial and frequency patterns of drought using a potential drought hazard mapping approach," International Journal of Climatology, vol. 34, no. 1, pp. 61-80, 2014.

[80] K. K. Kumar and T. V. R. Rao, "Dry and wet spells at Campina Grande-PB," Revista Brasileira de Meteorologia, vol. 20, no. 1, pp. 71-74, 2005.

[81] A. A. Tsonis and J. B. Elsner, "Global temperature as a regulator of climate predictability," Physica D: Nonlinear Phenomena, vol. 108, no. 1-2, pp. 191-196, 1997.

[82] A. A. Tsonis, "Is global warming injecting randomness into the climate system?” Eos, vol. 85, no. 38, pp. 361-364, 2004.

[83] M. C. Peel and T. A. McMahon, "Recent frequency component changes in interannual climate variability," Geophysical Research Letters, vol. 33, no. 16, Article ID L16810, 2006.

[84] X. J. Gao, Y. Xu, Z. C. Zhao, J. S. Pal, and F. Giorgi, "On the role of resolution and topography in the simulation of East Asia precipitation," Theoretical and Applied Climatology, vol. 86, no. 1-4, pp. 173-185, 2006.

[85] X. J. Gao, Y. Shi, R. Song, F. Giorgi, Y. Wang, and D. Zhang, "Reduction of future monsoon precipitation over China: comparison between a high resolution RCM simulation and the driving GCM," Meteorology and Atmospheric Physics, vol. 100, no. 1-4, pp. 73-86, 2008. 

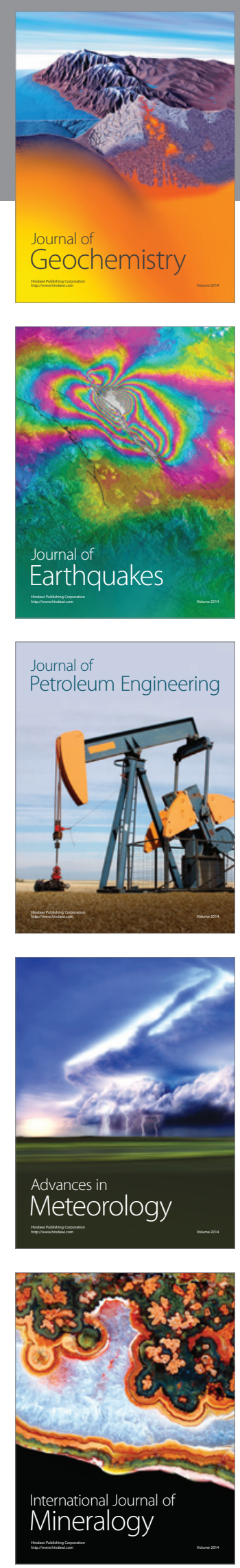
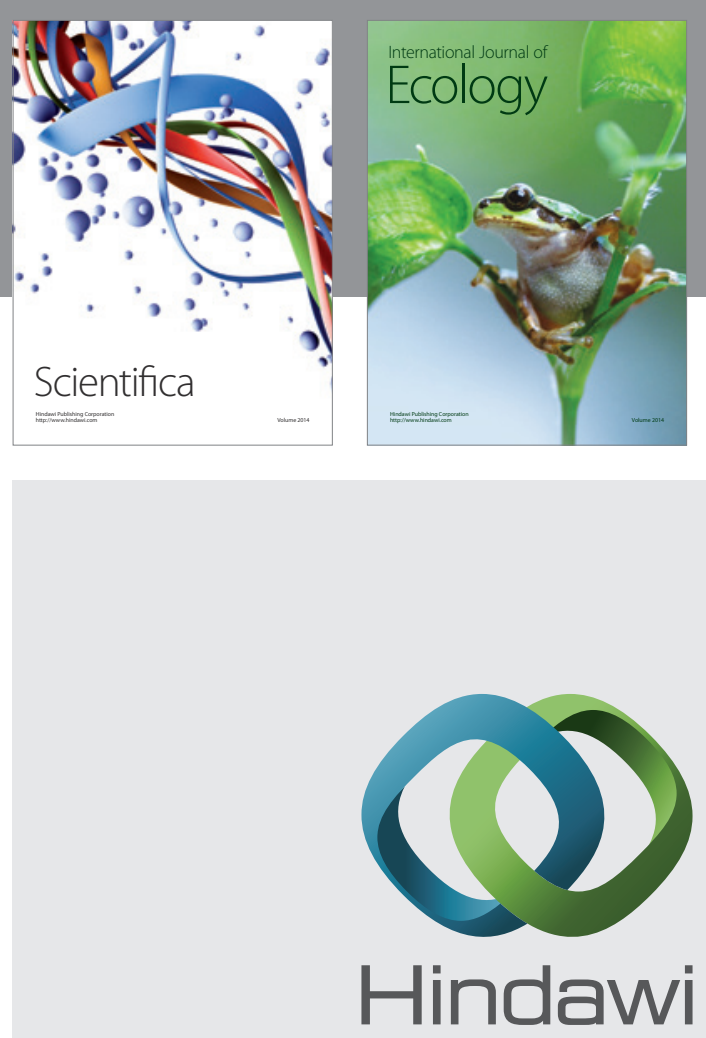

Submit your manuscripts at

http://www.hindawi.com
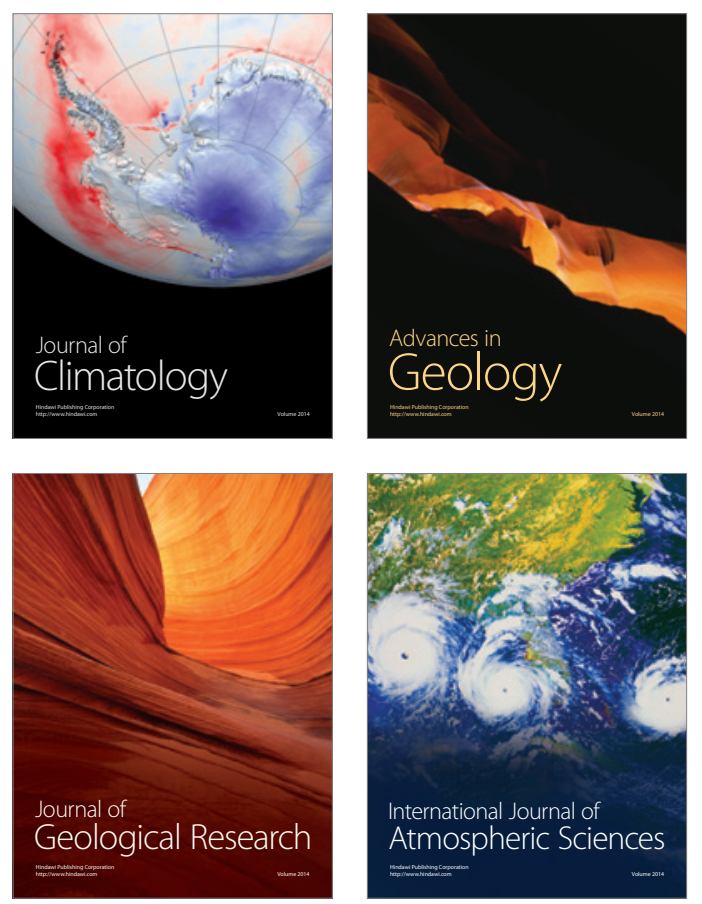

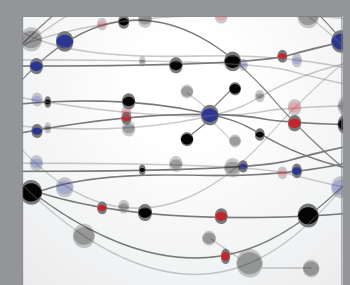

The Scientific

\section{World Journal}
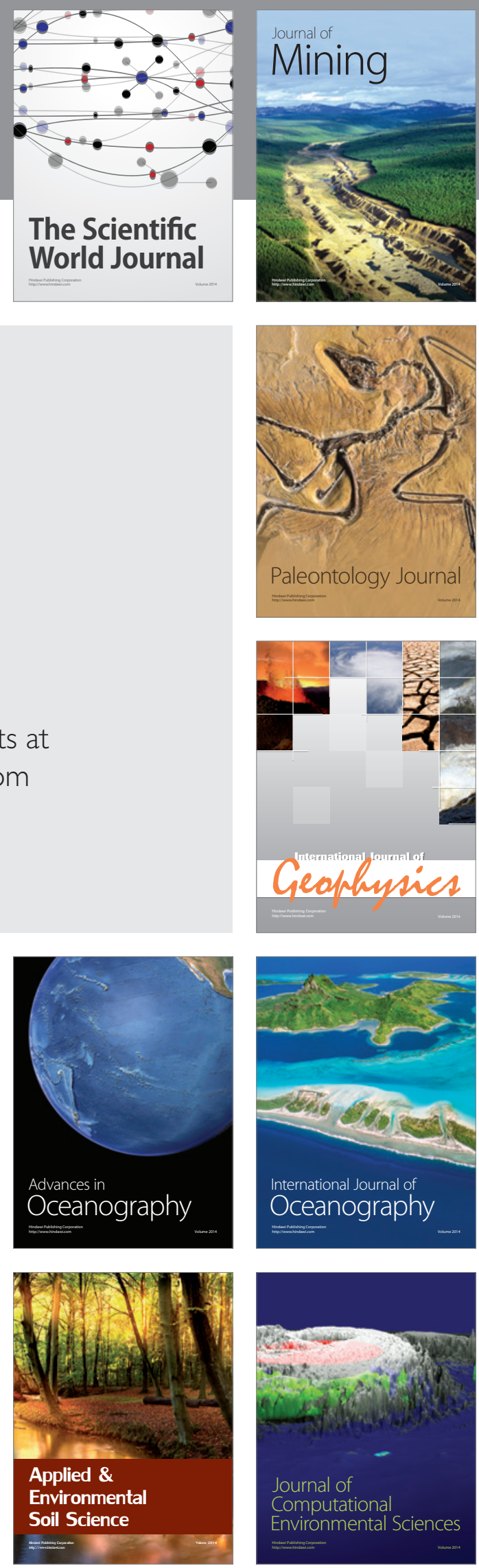